\title{
DYNAMIC WEAKENING (EXTINCTION) OF SIMPLE HYDROCARBON-AIR COUNTERFLOW DIFFUSION FLAMES BY OSCILLATORY INFLOWS
}

\author{
G. Pellett ${ }^{1^{\star}}$, A. Kabaria ${ }^{2}$, B. Panigrahi ${ }^{3}$, K. Sammons $^{4}$, J. Convery ${ }^{5}$, and L. Wilson ${ }^{6}$
}

\begin{abstract}
This study of laminar non-premixed HC-air flames used an Oscillatory-input Opposed Jet Burner (OOJB) system developed from a previously well-characterized 7.2-mm Pyrex-nozzle OJB system. Over 600 dynamic Flame Strength (FS) measurements were obtained on unanchored (free-floating) laminar Counterflow Diffusion Flames (CFDF's). Flames were stabilized using plug inflows having steady-plus-sinusoidal axial velocities of varied magnitude, frequency, $f$, up to $1600 \mathrm{~Hz}$, and phase angle from 0 (most data) to 360 degrees. Dynamic FS is defined as the maximum average air input velocity ( $U_{\text {air, }}$, at nozzle exit) a CFDF can sustain before strain-induced extinction occurs due to prescribed oscillatory "peak-to-peak" velocity inputs superimposed on steady inputs.
\end{abstract}

Initially, dynamic flame extinction data were obtained at low $f$, and were supported by $25-120 \mathrm{~Hz}$ HotWire cold-flow velocity data at nozzle exits. Later, expanded extinction data were supported by 4-1600 $\mathrm{Hz}$ Probe Microphone (PM) pk/pk $P$ data at nozzle exits. The PM data were first obtained without flows, and later with cold stagnating flows, which better represent speaker-diaphragm dynamics during runs. The PM approach enabled characterizations of Dynamic Flame Weakening (DFW) of CFDF's from 8 to $1600 \mathrm{~Hz}$. DFW was defined as \% decrease in FS per Pascal of pk/pk $P$ oscillation, namely, DFW = $100 \mathrm{~d}\left(U_{\text {air }} / U_{\text {air, } O \mathrm{~Hz}}\right) / \mathrm{d}($ pkpk $P)$. The linear normalization with respect to acoustic pressure magnitude (and steady state (SS) FS) led to a DFW unaffected by strong internal resonances.

For the $\mathrm{C}_{2} \mathrm{H}_{4} / \mathrm{N}_{2}$-air system, from 8 to $20 \mathrm{~Hz}$, DFW is constant at $8.52 \pm 0.20$ (\% weakening)/Pa. This reflects a "quasi-steady flame response" to an acoustically induced $\mathrm{d} U_{\text {air }} / \mathrm{d} P$. Also, it is surprisingly independent of $\mathrm{C}_{2} \mathrm{H}_{4} / \mathrm{N}_{2}$ mole fraction due to normalization by SS FS. From 20 to $\sim 150 \mathrm{~Hz}$, the $\mathrm{C}_{2} \mathrm{H}_{4} / \mathrm{N}_{2}$-air flames weakened progressively less, with an inflection at $\sim 70 \mathrm{~Hz}$, and became asymptotically insensitive (DFW 0) at $\sim 300 \mathrm{~Hz}$, which continued to $1600 \mathrm{~Hz}$. The DFW of $\mathrm{CH}_{4}$-air flames followed a similar pattern, but showed much greater weakening than $\mathrm{C}_{2} \mathrm{H}_{4} / \mathrm{N}_{2}$-air flames; i.e., the quasi-steady DFW ( 8 to $\sim 15 \mathrm{~Hz}$ ) was $44.3 \% / \mathrm{Pa}$, or $\sim 5 \mathrm{x}$ larger, even though the $0 \mathrm{~Hz}$ (SS) FS was only $3.0 \times$ smaller. The quasi-steady DFW's of $\mathrm{C}_{3} \mathrm{H}_{8}$-air and $\mathrm{C}_{2} \mathrm{H}_{6}$-air were intermediate at 34.8 and $20.9 \% \mathrm{~Pa}$, respectively. The DFW profiles of all four fuels, at various frequencies, correlated well but non-linearly with respective SS FS's. Notably, the DFW profile for $\mathrm{C}_{3} \mathrm{H}_{8}$-air fell more rapidly in the range $>15$ to $60 \mathrm{~Hz}$, compared with the 1- and 2-carbon fuels. This may indicate a shift in chemical kinetics, and/or $\mathrm{O}_{2}$ transport to a flame that moved closer to the fuel-side.

\footnotetext{
${ }^{1}$ Senior Research Scientist, Hypersonic Airbreathing Propulsion Branch/RTG, MS 168, NASA Langley Research Center, Hampton, VA 23681; Senior Member, AIAA g.l.pellett@larc.nasa.gov

${ }^{2}$ NASA-VA Governor's School; now Harvard University, Cambridge, MA

${ }^{3}$ NASA-VA Governor's School; now University of Virginia, Charlottesville, VA

${ }^{4}$ NASA-VA Governor's School; now Old Dominion University, Norfolk, VA

${ }^{5}$ Graduate R.A., VPI \& SU, Blacksburg, VA; Graduate Fellow, National Institute of Aerospace, Hampton, VA; Member AIAA

${ }^{6}$ Lockheed Martin Space Operations, Hampton, VA
}

Copyright (C) 2005 by the American Institute of Aeronautics and Astronautics, Inc. No copyright is asserted in the United States under Title 17, U.S. Code. The U.S. Government has a royalty-free license to exercise all rights under the copyright claimed herein for Governmental purposes. All other rights are reserved by the copyright owner.

Approved for public release; distribution is unlimited. 
In conclusion, Dynamic Flame Weakening limits appear significant and unique for each fuel, and correlate closely, but non-linearly, with Steady-State Flame Strengths at any given frequency. For reasons unknown, the dynamic flames didn't weaken more at intermediate frequencies (e.g., at 20-50 $\mathrm{Hz}$ ) than they did at low frequencies $(<15 \mathrm{~Hz})$, where quasi-steady weakening appears to dominate. Quasi-steady flame weakening ostensibly represents a transient input strain rate maximum that just exceeds the steady-state strain-rate-limited extinction limit for a few cycles. Clearly, further detailed mechanistic understanding is needed in the fall-off region.

\section{Introduction}

Turbulent non-premixed hydrocarbon-air flames are frequently exposed to strong acoustic fields in practical combustion devices, but research in characterizing the fundamentals of flame perturbation has been sporadic [1-5]. Although our applied objective is to understand key physical/chemical flameholding processes in hydrocarbon-fueled airbreathing scramjets (see [22] for a detailed review of flameholding processes and ground-test effects), such engines represent but one of many different applications that may be affected. Despite the surge of interest in unsteady flames during the early 1990's [3-15], much remains to be understood regarding specific physical/chemical effects of acoustic oscillations on the structure and extinction of even the simplest dynamically strained diffusion flames. Most of the current knowledge stems from large-activation-energy asymptotic analyses $[6,8,9]$ and numerical simulations $[5,7,11,12]$. The few known experimental studies have emphasized detailed nonintrusive measurements of species, temperature, and velocity, and resultant axial strain rates in methane-air and propane-air systems at relatively low frequencies [10,13-15].

This paper presents an idealized experimental study of four gaseous hydrocarbon-air systems, using an Oscillatory-input convergent-nozzle Opposed Jet Burner (OOJB) system developed from earlier steady-state studies [16-21]. It features a substantially improved analysis of the ethylene-air and methane-air dynamic extinction data presented in our previous paper, AIAA-2003-4634 [26], and it also contains new sets of ethane-air and propane-air data that exhibit intermediate behavior. Both features lead to a simpler and broader set of conclusions, compared to our initial publication.

Thus, about 600 dynamic-extinction "Flame Strength" measurements were obtained on unanchored (free-floating) laminar Counterflow Diffusion Flames (CFDF's), stabilized by steady input flows, and perturbed by superimposed sinusoidal velocity inputs (mostly in-phase). We define steady-state Flame Strength, FS, as the maximum average air input velocity ( $U_{\text {air }}$ at nozzle exit) a CFDF can sustain before it extinguishes suddenly, due to increasing net heat loss and a precipitous decline in temperature [21]. Although the steady-state strength of a flame can, in principle, be defined more closely by measuring the maximum steady axial strain rate near the airside edge of the flame [21], such a measurement is inadequate for dynamic Flame Strength. This is because, under dynamic conditions, the input velocity gradient (strain rate) field varies complexly with axial position, and with the magnitude and frequency of applied input velocity oscillations (pk/pk $U_{\text {air }}$ ).

Although Dynamic FS might be gauged by a sinusoidal-maximum axial strain rate near the airside edge of a CFDF, that would only indirectly reflect maximum radial strain rate in the all-important flame core. And because the entire transient strain field varies complexly with the magnitude of sinusoidal input $\left(\mathrm{pk} / \mathrm{pk} U_{\text {air }}\right)$ and $f$, definitive flow-field measurements and deductions of transient temperature and transport effects are difficult, and unavailable. Finally, although pk/pk $U_{\text {air }}$ input magnitudes are theoretically derivable from measured acoustic pressure magnitudes (pk/pk $P$ ) when local acoustic impedance is accounted-for, such complex flow-field characterizations have not been done. Instead, global extinction parameters and Probe Microphone pk/pk $P$ cold-flow measurements were used to assess Dynamic FS.

Thus measurements of dynamic extinction were supported initially by limited Hot Wire, and later by extensive Probe Microphone, cold-input-flow calibrations. The latter enabled characterizations of the dynamic weakening of each hydrocarbon-air system at frequencies from 4 to $1600 \mathrm{~Hz}$. Quasi-steady weakening is measured at low frequencies (e.g., $\leq 15 \mathrm{~Hz}$ ), where the maximum $U_{\text {air }}$ attained slightly 
exceeds the $U_{\text {air }}$ for steady-state extinction. At progressively higher frequencies, a transition (decrease) in dynamic flame weakening occurs, which is known to be accompanied by increasing phase lags in diffusive transport. Finally, at still higher frequencies, flames regain their original "steady-state strength" as they become unresponsive to the rate-limited molecular diffusion of flame reactants and products.

The present data analyses and comparisons with published analytic and numerical results offer new insight on: The dynamic strain rate effects on quasi-steady extinction; the apparent effects of diffusivetransport phase lags with increasing frequency, in which diffusion flames might weaken even further as they depart from the quasi-steady state, and then "re-strengthen" at higher frequencies; and, the eventual development of complete insensitivity at high-frequencies.

Finally, with particular application to airbreathing scramjet engines, we recognize that critical early stages of localized subsonic "incipient" flameholding are typically associated with fuel injection processes that "feed" reacting recirculation zones having "sufficient" residence-time distributions [22]. Such incipient flames may be weakened and extinguished by acoustically-perturbed, frequencysensitive diffusion processes, such as $\mathrm{H}$-atom diffusion in a "laminar-flamelet-like" reaction zone. Because such limitations may cause the loss of "robust" flameholding, and possibly generalized flameout, it is important to characterize these dynamic effects and begin to assess the potential for their occurrence in scramjet designs. Thus it appears that detailed measurements of low frequency $(<200$ $\mathrm{Hz}$ ) acoustic fields are also needed to assess possible effects on critical flameholding in ground-based and flight tests of scramjet engine configurations.

\section{Experimental Approach}

The experimental approach follows earlier extensive studies of steady-state CFDF's using various nozzle and tube-OJB's [21], an initial study of the acoustic weakening of CFDF's using an oscillatoryinput $7.2 \mathrm{~mm}$ nozzle-OJB system [26] unchanged from the present OOJB system, and a more recent Work-in-Progress Poster presentation featuring a significantly improved analysis of dynamic flame weakening [27]. The current results include four major sets of data on the dynamic extinction of gaseous hydrocarbon-air systems, one of which was nitrogen diluted. The reanalyzed data, obtained as functions of applied pk/pk voltage magnitudes to twin speaker-drivers, are respectively combined with Hot Wire and Probe Microphone (PM) dynamic flow calibration data obtained under essentially identical conditions, except the PM speaker-calibration flows were significant (5 SLPM), and of course cold. Thus dynamic flame weakening is quantified in terms of axially applied sinusoidal velocity or "equivalent" pressure oscillations at the nozzle exits. The combined results thus provide idealized characterizations of flame weakening effects due to forced oscillations of fuel and air input velocities on the subject laminar counterflow diffusion flame (CFDF) systems.

The dynamic OOJB system shown in Fig. 1 consists of several subsystems (see [18-21]). First a mass flow-metered gas mixing system delivers a fuel mixture (sometimes $\mathrm{N}_{2}$-diluted), containing one of the gaseous hydrocarbon fuels, to the upper speaker-driver and then down to the nozzle exit. The fuel mixture enters a shallow cone-shaped plenum $(\sim 6-\mathrm{cm}$ high at the center), bounded at the top by a 20 $\mathrm{cm}$ diameter polypropylene-coated speaker-driver diaphragm, and below by a machined metal plate. The plate has a $2.5-\mathrm{cm}$ diameter hole, centered on the speaker axis, which is O-ring sealed to a vertically-oriented $2.2-\mathrm{cm}$ i.d. Pyrex tube that effectively extends $38.3-\mathrm{cm}$ to the nozzle exit. Similarly, mass flow-metered air is delivered through an identical speaker-driver system at the bottom. Thus in each experiment, nearly-uniform laminar jets of fuel mixture and air are impinged through matched pairs of $7.2 \mathrm{~mm}$ convergent Pyrex nozzles, to form a free-floating flame (after ignition); this flame moves vertically with any flow imbalance (hence free floating), and is always kept centered. The nozzle gap is fixed at two exit diameters. The nozzle area contraction ratio is $\sim 9: 1$ with convergence over $\sim 1$ tube diameter, and each nozzle is slightly "recurved" near the exit. The resultant plug-flow velocity field, which exhibits a shallow dish-shaped central depression (consistent with numerical predictions by Rolon et al.), has been previously characterized using LDV and PIV measurements $[18,19]$. The Pyrex nozzles, insulated by blocks of silica foam insulation, are mounted in a rigid ceramic fiber box with three Pyrex windows and a porous top of sintered metal or ceramic fiber. Argon or $\mathrm{N}_{2}$ bath gas, dispersed 
radially via a jet near the bottom of the box, prevents/inhibits extraneous combustion outside the central impingement region, and thus minimizes adverse flame attachment, buoyancy, and visibility effects. Fuel and air component flows were hand-controlled using micrometer valves, and monitored by the calibrated mass flowmeters.

\section{Steady State Flame Strength Measurements}

To obtain steady-state extinction of a CFDF, the mass flows of fuel mixture and air are slowly increased simultaneously, so the disk flame, located primarily on the airside, is always centered and free-floating [16-21]. Manual control of flame centering is monitored visually, and also through a TV display from a horizontally oriented focusing schlieren system [18]. Whenever $\mathrm{N}_{2}$-diluted fuels are used, the fuel is fixed at a target rate and $\mathrm{N}_{2}$ is increased. In this case, because metered fuel and diluent flows are blended in a small glass bead mixer, and then pass through a substantial "dead volume" in the fuel speaker plenum and tube/nozzle system, diluent flow is increased very slowly so the drift in mixture composition has sufficient time to reach the nozzle exit. After each extinction (blowoff), or rupture of the (very) flat disk-shaped-flame structure (monitored via focusing schlieren), a residual ring-shaped flame quickly establishes at a stable location centered near the stagnation point, where the degree of mixing is high. Mass flow rates of each component are then recorded.

The global nozzle-area-average jet velocity used to evaluate flame strength (FS) at extinction, $U_{\text {air, }}$, is calculated from the mass flow of dry "service" air standardized at $273^{\circ} \mathrm{K}$ and $1 \mathrm{~atm}$, and measured nozzle exit diameter, $7.2 \mathrm{~mm}$. The $U_{\text {fuel }}$ is evaluated similarly from component mass flows.

Corresponding Reynolds numbers are generally less than 1500, but are not so low that CFDF's are unacceptably thick or non one-dimensional.

To restore the ring-like "tribrachial" or "edge" flame to a disk flame, respective flows are gradually decreased, so the slowly shrinking ring approaches $\sim 1$ jet diameter near the stagnation surface. At flame restoration the ring suddenly propagates inward and shifts axially (say, $\sim 1 \mathrm{~mm}$ ) to the airside. After flame restoration, another set of extinction/restoration measurements is obtained for replication purposes.

In previous studies of $\mathrm{H}_{2}$-air and $\mathrm{HC}$-air systems, flame restoration was found independent of jet diameter, and a large hysteresis in exit velocity existed between extinction and restoration [16-21]. It was concluded that flame restoration occurs as a velocity-limited piloted-reignition along a thin stagnated region containing inter-diffused jet flows; or, when the inward "stretched laminar burning velocity" finally exceeds the maximum outward radial velocity [21]. Recent very detailed numerical simulations $[23,24,28]$ fully support our earlier simplified description. Note, for extinction-restoration hysteresis, the radial strain rate in the central stagnation region must always be smaller than that required for extinction. Otherwise blowoff and restoration will occur at essentially the same flow rates which was observed for methane-air using (unnecessarily) small 2.7-mm tube-OJB's [16].

\section{Dynamic Flame Strength Measurements}

Dynamic extinction measurements were obtained using the same basic flow technique as in the steadystate measurements, except the twin speakers were driven in-phase (almost always, unless noted) by one of several pre-selected applied voltages, and frequencies. Thus, a waveform generator was first set to a desired frequency and a sinusoidal output of 1 volt amplitude. This became input to a variable speaker-amplifier. Twin analog outputs from the amplifier powered the twin speakers. The amplifier outputs were manually adjusted to selected peak-to-peak (pk/pk) voltages while viewing waveform displays on a LeCroy digital oscilloscope. Once the speaker-drivers were set identically, a dynamic Flame Strength measurement was obtained using the same flow procedures as discussed above. If flow reversal in the nozzles appeared likely, based on previous hot-wire flow calibrations (described below), and/or the flame was too unstable, based on visual and focusing schlieren observations and also difficulties in maintaining a centered and unanchored flame, lower pk/pk applied voltages were used. 
During very early stages of the study (with B. Reid in 1998 [26]), dynamic extinction measurements were obtained for the $18 \% \mathrm{H}_{2}$-air and $\mathrm{CH}_{4}$-air systems over a range of pk/pk speaker-driver voltages, at respective frequencies of $30,60,120 \mathrm{~Hz}$; and later at $25,50,100 \mathrm{~Hz}$. Thus some limited sets of dynamic flame strength data corresponded to known speaker-voltage waveforms. To analyze these FS data in terms of physically realistic air and fuel input velocities / strain-rates that effectively characterize extinction limits, independent velocity information at each nozzle exit was needed as a function of applied speaker voltage. (Note that limited sets of definitive measurements of dynamic axial strain rate near the airside flame edge have been reported by others [13-15].)

Thus limited Hot-Wire velocimetry measurements of cold flows at the nozzle exits were obtained at three frequencies each, over two distinct time periods (2000 and 2001) [26]. In each case, pk/pk sinusoidal air and fuel cold-flow input velocity magnitudes were measured at the respective nozzle exits corresponding to various sets of pk/pk speaker voltage magnitudes, steady input mass flows, and applied frequency. The respective Hot-Wire velocity data sets were analyzed using three levels of empirical curve fits. Thus dynamic extinction data could be transformed and analyzed as functions of $\mathrm{pk} / \mathrm{pk}$ sinusoidal air and fuel input velocity magnitudes. The velocity magnitude inputs were calculated as empirical functions of pk/pk speaker voltage magnitudes, mass flow rates of air and fuel, and frequency up to $120 \mathrm{~Hz}$, using an expression for $U_{\text {air }}$ that produced nearly identical results compared with the later set of independently derived expressions for $U_{\text {air }}$ and $U_{\text {fuel }}$ (unpublished data, Clare Mc Namara (2000), Princeton University; and Rachel Johnson (2001), The Air Force Academy).

Upon combining the dynamic input velocity and extinction data for $\mathrm{C}_{2} \mathrm{H}_{4} / \mathrm{N}_{2}$-air systems, it was found, for any given raw (uncorrected) $\mathrm{C}_{2} \mathrm{H}_{4}$ mass flow, i.e., 3, 5, or $8 \mathrm{SLPM}$, the measured flame strength, $U_{\text {air, }}$, was a linear decreasing function of the $\mathrm{pk} / \mathrm{pk}$ velocity magnitude of the sinusoidal input, $\mathrm{pk} / \mathrm{pk} U_{\text {air }}$. The resultant negative slopes of these data were primarily a function of frequency, but they also varied with the respective input mass flow rates of $\mathrm{C}_{2} \mathrm{H}_{4}$. (Later on, slope variations for the three different input mass flows of $\mathrm{C}_{2} \mathrm{H}_{4}$ were effectively "normalized-out" using corresponding steady-state flame strengths of $\mathrm{C}_{2} \mathrm{H}_{4} / \mathrm{N}_{2}$-air, to produce a singular Dynamic Flame Weakening response for the $\mathrm{C}_{2} \mathrm{H}_{4} / \mathrm{N}_{2}$-air systems; see Results section.)

Errors in extinction limits stemmed from various sources; and some are compensated-for internally. For example, according to the ideal gas law, absolute jet velocities at constant mass flow vary linearly with input temperature. Hence mass inflow measurements are unaffected by local variations in gas velocity caused by jet temperature variations, and resultant "density-weighted" extinction limits have been found independent of such linear variations in gas velocity up to $\sim 600 \mathrm{~K}$ [21]. Thus potential data scatter due to temperature variation is effectively nulled, which is especially helpful when heated fuel jets are required [17]. However, variations in atmospheric pressure do affect the data slightly. These have not been routinely accounted-for until very recently [29], where $U_{\text {air }}$ calculated at $300 \mathrm{~K}$ is now routinely multiplied by the ratio $((29.92 \mathrm{in} \mathrm{Hg}) /(\text { Barometric Pressure, in } \mathrm{Hg}))^{3}$. Although the same nozzle-OJB was used throughout this study, on an absolute basis the calculated jet exit velocities are sensitive to (measured) jet diameter squared, and strain rates are sensitive to jet diameter cubed. This can be important when results are compared from different-size OJBs.

\section{Results}

\section{Steady State Flame Strength}

Steady-state extinction results for $\mathrm{C}_{2} \mathrm{H}_{4} / \mathrm{N}_{2}$-air CFDF's, shown in Fig. 2, exhibit typical data reproducibility and variation of $\mathrm{FS}$ with input mole fraction, for a $\mathrm{N}_{2}$-diluted gaseous hydrocarbon fuel. $A$ minor extrapolation of the asymptotic data trend, using a simple polynomial fit (previously wellestablished [16-21]), indicates a FS of $310 \mathrm{~cm} / \mathrm{s}$ for $100 \% \mathrm{C}_{2} \mathrm{H}_{4}$-air flames (at $273 \mathrm{~K}$ ). This corresponds to an Applied Stress Rate of 310/0.72 = $4301 / \mathrm{s}$, and a global axial strain rate at the airside edge of $2 \times 430=8601 / \mathrm{s}$ at $273 \mathrm{~K}$, for an idealized 1-D CFDF with uniform axial velocity input [21]. 
The asymptotic limit represents a chemical kinetic limited reaction rate for a CFDF that is unaffected by the diffusion rate and thermodynamic properties of the $\mathrm{N}_{2}$. The indicated raw $\mathrm{C}_{2} \mathrm{H}_{4}$ inputs, in uncorrected Standard Liters per Minute (SLPM), do not contain a factor of 0.69 for ethylene mass flows (based on heat capacity) that is otherwise applied to all calculated quantities.

The steady-state $\mathrm{FS}$ for $100 \% \mathrm{C}_{2} \mathrm{H}_{4}$-air can be compared with previous measurements for $100 \% \mathrm{CH}_{4}-$ air and $18 \% \mathrm{H}_{2}$-air CFDF's obtained using the same $7.2 \mathrm{~mm} \mathrm{OJB}$, and $100 \% \mathrm{H}_{2}$-air CFDF's that were characterized earlier using a series of scaled OJB's [21]. Based on the previous data $[21,26,27]$ and also an earlier FS of $113.6 \mathrm{~cm} / \mathrm{s} @ 300 \mathrm{~K}$ for $\mathrm{CH}_{4}$-air, the $\mathrm{C}_{2} \mathrm{H}_{4}$-air flame is 3.0 times stronger than the $\mathrm{CH}_{4}$-air flame. And based on the extensive $\mathrm{H}_{2}$-air nozzle-OJB results in [21], the $\mathrm{C}_{2} \mathrm{H}_{4}$-air flame is 12.0 times weaker than the $100 \% \mathrm{H}_{2}$-air CFDF.

\section{Dynamic FS, and Data Transformation using Limited Sets of Hot-Wire Velocimetry of Cold Flows}

Fig. 3 exemplifies a transformation / analysis of the dynamic extinction data, using the previous Hot Wire velocimetry data to quantify the effect of sinusoidal pk/pk exit velocity magnitudes (from sinusoidal pk/pk voltage magnitudes to speakers) on the dynamic Flame Strength of $\mathrm{C}_{2} \mathrm{H}_{4} / \mathrm{N}_{2}$-air CFDF's, for 3 SLPM (raw) $\mathrm{C}_{2} \mathrm{H}_{4}$ input flows. Thus the abscissa is based on our earlier [26] empirical analysis of Hot Wire data on nozzle exit flows, up to $120 \mathrm{~Hz}$, and then an over-extrapolation of the empirical pk/pk exit velocity magnitude function to higher frequencies (beyond $120 \mathrm{~Hz}$ ).

The Fig. 3 data apply to a selected range of frequencies (100-500) over which the weakening effects on flame strength appear to grow large, and then become negligible. The data at both 100 and $200 \mathrm{~Hz}$ show the dynamic response of flame strength to "projected" pk/pk $U_{\text {air }}$ is linear, even though the magnitudes of oscillation are large compared with the mean $U_{\text {air. }}$. Checks at other flows and frequencies indicated similar linear responses, even under rare conditions where local flow reversal (which we carefully avoid) is known to have occurred (from HW data traces). The large change in projected dynamic response (slope) in Fig. 3, that occurs between 450 and $500 \mathrm{~Hz}$, appears to suggest some sort of transition, where Flame Strength may no longer be affected.

Thus the linear slopes in Fig. 3, which apply at particular frequencies and are well defined in numerous similar plots, are referenced to the magnitude of our earlier empirical pk/pk exit velocity function (inappropriately extrapolated to frequencies higher than $120 \mathrm{~Hz}$ ), and seem to represent the sensitivity of dynamic flame strength to projected pk/pk sinusoidal velocity inputs at various frequencies. These slopes were initially thought to provide a useful measure of the dynamic response of flame extinction to imposed velocity oscillations, as a function of frequency (summarized later in Fig. 5).

Fig. 4 shows a wide range of dynamic extinction results, as an extension of the steady state results in Fig. 1. It represents $\sim 200 \mathrm{C}_{2} \mathrm{H}_{4} / \mathrm{N}_{2}$-air CFDF measurements made early in the program. These were obtained using various sinusoidal speaker-voltage inputs that produced various predicted axial velocity input magnitudes, $\mathrm{pk} / \mathrm{pk} U_{\text {air }}$, at preset frequencies. For certain mid-range frequencies, the data illustrate significant impacts of oscillatory velocity inputs on dynamic Flame Strength (up to a factor of 2), over a wide range of raw $\mathrm{C}_{2} \mathrm{H}_{4}$ inputs and resultant $\mathrm{C}_{2} \mathrm{H}_{4} / \mathrm{N}_{2}$ mole fractions. At frequencies of 500 to $1600 \mathrm{~Hz}$ there is very little effect of input oscillation on flame strength compared to $0 \mathrm{~Hz}$ (steady-state). At very low frequencies (e.g. 4 and $10 \mathrm{~Hz}$ ) some minor "apparent" weakening is evident, but this occurred at relatively large amplitudes of oscillation that added to the imposed mean velocity (strain rate).

Fig. 5 summarizes the resultant "projected dynamic velocity response" of Flame Strength, obtained from the 200 early measurements of $\mathrm{C}_{2} \mathrm{H}_{4} / \mathrm{N}_{2}$-air extinction in Fig. 4, and based on the empirically derived velocity magnitude projections from Hot Wire data. Because the respective data sets for 3,5 , and $8 \mathrm{SLPM} \mathrm{C} \mathrm{H}_{4}$ exhibit very similar trends and slightly more scatter (shown later), data averaging is used to define the apparent effect of frequency more clearly. The 4 and $10 \mathrm{~Hz}$, data are believed to be essentially quasi-steady, so that potentially limiting molecular / free-radical transport processes are fast enough to follow the oscillations in input strain rate. In such cases, flame extinction should occur near peak input velocity, which approximately equals $U_{\text {air }}+\left(\mathrm{pk} / \mathrm{pk} U_{\text {air }}\right) / 2$. At higher frequencies, however, 
the "dynamic velocity response" of Flame Strength grows more negative until, just beyond $250 \mathrm{~Hz}$, it appears to decrease steeply by a factor of four. And shortly after this fall-off, a very steep recovery occurs between 450 and $500 \mathrm{~Hz}$, which appears to define a highly weakened "notch" region terminated by a steep high-frequency cut-off limit. The reproducibility of these extinction data is remarkably good at fixed frequencies (typically $\pm 3 \%$ ), even at highly sensitive frequencies, e.g. $475 \mathrm{~Hz}$. At frequencies above $500 \mathrm{~Hz}$, the CFDF's become minimally responsive, and tend asymptotically to become totally unresponsive with respect to extinction.

At this point, the likelihood of significant acoustic resonance effects became clear. The small waviness in the spline fits of Fig. 5 suggested minor resonance phenomena occurred over some regions; however, the large and abrupt changes in dynamic velocity response around the "notch" region suggested that major resonance phenomena were also occurring. A simple calculation pointed to the problem. The 38-cm length of Pyrex tube to each nozzle exit, plus $\sim 6-\mathrm{cm}$ of dead space between the tube and the speaker diaphragm in the plenum region, coincides with two wavelengths of sound at 395 $\mathrm{Hz}(=(348 \mathrm{~m} / \mathrm{s}) /(0.44 \mathrm{~m})(1 / 2)$, which would promote constructive interference within each speaker-tube system. Although obvious anomalous changes in sound intensity were not recalled when frequency was changed at fixed applied voltage, it was clearly important to conduct a sound measurement survey.

\section{Probe Microphone Measurements}

A wide-frequency-range calibrated Probe Microphone system was used to measure the localized sound pressure field, at the air (and fuel) nozzle exits, as a function of frequency, both without flows, and later with fixed flows of $\mathbf{5}$ SLPM $\mathbf{N}_{\mathbf{2}}$. The purpose of the initial PM measurements at zero flow [26] was to characterize resonance phenomena and provide a quantitative basis for characterizing dynamic flame response. Later, it was recognized that the dynamics of each speaker diaphragm, and resultant sound pressure measurements, were significantly sensitive to the pressures of gas flowing through each speaker plenum to the respective nozzles located downstream. Notably, this was already known to be true for the earlier Hot Wire velocity calibration measurements.

Both sets of the Fig. 6 results show substantial effects of acoustic resonance in the system, equivalent to constructive interference for 2,1,1/2, and 1/3 wavelengths. And, Fig. 6 also shows that significant acoustic pressure differences exist, at both low and middle frequencies, between PM data obtained with zero flows and with fixed flows of 5 SLPM N $N_{2}$. More detailed tests (not shown) at key frequencies, and with flows of $\mathrm{N}_{2}$ between 0 and 8 SLPM, indicated that most of the acoustic pressure differences occurred from zero to relatively low flows, and the detailed data obtained at 5 SLPM adequately represented the experimental range of flows encountered.

Finally, while it is recognized that the Euler equation can be solved numerically with appropriate boundary conditions, to obtain the corresponding oscillating exit velocity field in our confined system, where acoustic impedance is important, this has not been attempted. Meanwhile, the dynamic extinction results are analyzed in a similar manner as before, but now using the 5 SLPM sound pressure magnitude data as follows, instead of the frequency-limited velocity magnitudes.

\section{Transformation of Dynamic Data using Probe Microphone Measurements}

Fig. 7 shows the same dynamic extinction data as in Fig. 3, except the new abscissa is measured pk/pk sinusoidal pressure magnitude at the air nozzle exit, based on zero cold flows. The data are similarly linear at each frequency, and thus slopes denoted as "dynamic pressure response" are defined. Since no evidence of significant non-linearity was found in the complete dynamic extinction data set for ethylene, all the data can be analyzed (as before) as a function of frequency. Although corresponding $\mathrm{pk} / \mathrm{pk}$ sinusoidal velocity magnitudes are clearly preferable to $\mathrm{pk} / \mathrm{pk}$ pressure magnitudes, to allow a more physically meaningful analysis of the results, this would require a solution of the Euler equation for the OOJB system, which is presently unavailable.

As a final step, the same dynamic extinction data shown in Figs. 3, and then reanalyzed in Fig. 7, are corrected in Fig. 8 as a function of pk/pk sinusoidal pressure magnitude at the air nozzle exit, based on 
5 SLPM flows. The resultant "corrected" dynamic pressure response slopes in Fig. 8 (for 3 SLPM $\mathrm{C}_{2} \mathrm{H}_{4}$ ) were then coupled with numerous other slope results from similar data plots (not shown), and finally assessed as a function of frequency. As with the first analysis using PM data based on zero cold flows, the original "notch" in the dynamic-velocity-response data (Fig. 5) continued to be entirely absent as a result of normalizing the dynamic extinction data using PM data based on 5 SLPM flows. At this point the entire set of dynamic pressure response results for the $\mathrm{C}_{2} \mathrm{H}_{4} / \mathrm{N}_{2}$-air system, based on 3,5 , and $8 \mathrm{SLPM} \mathrm{C}_{2} \mathrm{H}_{4}$ flows, could be examined in an attempt to rationalize the results.

\section{Refinement of the Flame Response Function for the $\mathrm{C}_{2} \mathrm{H}_{4} / \mathrm{N}_{2}-$ Air System}

Once the entire set of dynamic Flame Strength data for the $\mathrm{C}_{2} \mathrm{H}_{4} / \mathrm{N}_{2}$-air system was reanalyzed, to obtain linear slopes as a function of pk/pk pressure magnitude based on the 5 SLPM PM calibration, a plot of the raw Dynamic Flame Weakening data could be examined as a function of frequency, as shown in Fig. 9. Several important features are evident. First the respective raw DFW data for the three different ethylene flow rates exhibit significant differences, especially in the 8 to $50 \mathrm{~Hz}$ range. This suggests the results might be normalized by Steady-State Flame Strength to collapse the data to a singular function (discussed below). Second, a fairly well defined region of Quasi-Steady responses appears to exist at frequencies up to $20 \mathrm{~Hz}$. Third, a much different mid-frequency transition is evident, and the "high-frequency" cutoff beyond $200 \mathrm{~Hz}$ is followed by an asymptotic approach to "complete insensitivity" at frequencies from $\sim 300 \mathrm{~Hz}$ to $1600 \mathrm{~Hz}$, the limit of this study. And, as noted above, the former "notch" in dynamic-velocity-response data effectively disappeared entirely as a result of normalizing the dynamic Flame Strength data with PM pressure data.

Fig. 10 shows a complete set of fully normalized DFW results for the ethylene-air system. These were obtained after the raw data in Fig. 9 were normalized by Steady-State Flame Strengths for the respective ethylene flows of 3,5 , and $8 \operatorname{SLPM}\left(U_{\text {air,ss }}=210.8,256.4\right.$, and $\left.289.6 \mathrm{~cm} / \mathrm{s}\right)$; the results were also multiplied by 100 to define the percent Dynamic Flame Weakening per unit of pk/pk pressure magnitude $(\mathrm{Pa})$. Thus the raw Dynamic Flame Weakening results in Fig. 9 collapsed to a single curve in Fig. 10, which characterizes the ethylene response independent of its mole fraction in mixtures with $\mathrm{N}_{2}$. Note the DFW data in the 8 to $100 \mathrm{~Hz}$ range were most affected, with a substantial reduction of "data scatter" for the 3,5, and 8 SLPM ethylene mass flows. These data represent a respectably large range of Steady State Flame Strengths and ethylene mole fractions.

\section{Normalized Dynamic Flame Weakening of Methane-, Ethane-, and Propane-Air CFDF's}

Fig. 11 shows a collective plot of the entire set of normalized Dynamic Flame Weakening results for hydrocarbons in this study, including recent data for the three additional systems. Clearly, the collective results show that methane flames are weakened to a much greater extent than ethylene flames. The propane and ethane flames exhibit intermediate behavior. Also, the "knee like" transition from quasisteady extinction, to "progressive strengthening" of flames in the "falloff" region, occurs at progressively higher frequencies as the fuel changes from methane to ethylene. Notably this transition was predicted by Egolfofopoulos and Campbell [11], who used an analogous approach to Stokes' Second Problem that describes the attenuation of oscillations by diffusion. Because all the data are normalized with respect to Steady-State Flame Strengths (e.g., $U_{\text {air,ss }}=114.3 \mathrm{~cm} / \mathrm{s}$ at $300 \mathrm{~K}$ for methane), the absolute differences in Flame Response between ethylene and methane are somewhat smaller.

Finally, Fig. 12 shows a summary crossplot of all the fully normalized Dynamic Flame Weakening vs frequency results in Fig. 11, as a function of Steady State Flame Strength, $U_{\text {air,ss, }}$, for all the HC-Air systems studied. Clearly, the respective DFW's of $\mathrm{CH}_{4}-$ air, $\mathrm{C}_{3} \mathrm{H}_{8}-$ air, $\mathrm{C}_{2} \mathrm{H}_{6}$-air, and $\mathrm{C}_{2} \mathrm{H}_{4} / \mathrm{N}_{2}$-air flames (in order of decreasing DFW) correlate remarkably well with the Steady State FS's (in order of increasing SS FS's). The resultant power law exponents vary from -1.5 for Quasi-SS limits at $<15 \mathrm{~Hz}$, to -1.0 at $100-200 \mathrm{~Hz}$, to $\sim 0$ beyond $300 \mathrm{~Hz}$. Note that the Quasi-SS limits place an upper bound on Dynamic Flame Weakening. Although close inspection of the propane-air results in Fig. 11 indicates the relative decrease in DFW is clearly greater in the $f$ range, $15-80 \mathrm{~Hz}$, than for the other fuels, the Fig. 12 correlation still shows that Dynamic Flame Weakening of all the flames in this study, over the entire range of important frequencies, is always greatest for flames that are weakest in the Steady-State. 
Finally, the above departure of propane results may be a first indicator of additional chemical kinetic effects, and/or it may reflect a change in CFDF structure in which the flame zone is closer to the stagnation plane.

\section{Effects of Input Phase on Dynamic Flame Response}

It was considered important, from both theoretical and practical standpoints, to measure the possible effects of fuel-air input phase differences on dynamic Flame Response. Note that an earlier single waveform preamplifier with twin output amplifiers was replaced by a system of twin preamplifiers, and an amplifier with a settable phase lag. In all cases the respective voltage waveforms applied to the twin speakers were monitored using a digital oscilloscope (LeCroy) system.

Fig. 13, which shows 3 SLPM ethylene results obtained at $150 \mathrm{~Hz}$, indicates there is a mild phase angle effect over the very large range investigated. Each data point represents at least duplicate determinations, and at zero phase the data point represents a grand average of measurements throughout the study.

Fig. 14 shows the additional phase-effect data obtained, which includes frequencies of $50,75,100,150$ and $200 \mathrm{~Hz}$. Although the data trends for the two higher frequencies are nearly flat (including the 150 $\mathrm{Hz}$ data discussed above), the average trends for the lower three frequencies trend upward and show increasing scatter, especially the 75 and $50 \mathrm{~Hz}$ results. The apparent upward trends between zero phase and 180 degrees might be rationalized on the basis that, e.g., a 180 degree shift at $50 \mathrm{~Hz}$ represents a "push-pull" oscillation that is effectively $100 \mathrm{~Hz}$. Despite the data scatter, best-fit zerophase intercepts agree very well with corresponding averaged values in the previously evaluated zerophase data for 3 SLPM ethylene, shown in Fig. 10 and 11.

\section{Implications for Scramjet Combustors}

Possible implications of the dynamic results for scramjet and other high speed combustion systems are certainly varied and difficult to determine, considering the known complexity of flameholding processes, reviewed in [22]. One relatively obvious approach for scramjet flameholding is to consider fundamental resonant frequencies in cavity pressure oscillations caused by ducted supersonic flows, and resultant turbulent shear layer flows, over both open and closed cavities [25]. For example, application of a "modified Rossiter" expression, reviewed in [25], predicts a fundamental frequency of $2960 \mathrm{~Hz}$ for a typical free stream air velocity of $1500 \mathrm{~m} / \mathrm{s}$ over an open cavity of $10-\mathrm{cm}$. length. Because this frequency is considerably beyond the present high-responsivity range for hydrocarbon-air combustionextinction, such induced oscillations may not affect open-cavity-based flameholding in this idealized case. Nevertheless, careful acoustic measurements and more detailed analyses of flameholding in various other fueled cavities and subsonic wake flows, especially in the vicinity of possibly-oscillating fuel jets, are needed to fully assess the potential for flame weakening effects in both test engines and flight vehicles.

\section{Findings and Concluding Remarks}

A unique idealized experimental study of the subject fuel-air systems was performed using an Oscillatory-input Opposed Jet Burner (OOJB) system. The study adds two new hydrocarbon data sets, and includes a significantly refined data analysis, compared to the author's previous paper, AIAA-20034634. Extensive dynamic-extinction "Flame Strength" (FS) measurements were obtained on unanchored (free-floating) laminar Counterflow Diffusion Flames (CFDF's), stabilized by steady input flows and perturbed by superimposed in-phase sinusoidal velocity inputs at both the fuel and air nozzle exits. Both limited Hot-Wire (HW) measurements of velocity fluctuation magnitudes at the nozzle exits, and much more extensive and accurate Probe Microphone (PM) measurements of acoustic pressure magnitudes, were obtained with cold flows and then used to analyze the dynamic Flame Strength data. 
It was very important to use PM measurements obtained when significant gas flows were maintained (a nominal mean flow of 5 SLPM was used), rather than earlier PM measurements obtained under zeroflow conditions, as was done in the author's previous paper, AIAA-2003-4634. This is because each speaker diaphragm needs to be positively pressurized by flowing fuel and air, to replicate normal run conditions with speaker-imposed oscillations during extinction measurements.

The steady state and dynamic CFDF extinction measurements in this study, coupled with the respective dynamic cold-flow nozzle-input calibrations, led to the following findings and conclusions:

(1) The $\mathrm{HC}$-air flame weakening results are unique but fundamentally consistent with limited published results on the structure and extinction (rare) of forced unsteady CFDF's. Available numerical simulations and sparse data indicate diffusive responses of key species (e.g. $\mathrm{H}$-atom, $\mathrm{H}_{2}, \mathrm{O}$ and $\mathrm{OH}$ ) control phase lags (relative to inputs) in concentration and temperature waves, which may weaken a flame. At high $f$, rate-limited diffusive responses ultimately lead to flame insensitivity, with no consequent weakening.

(2) The $0 \mathrm{~Hz}$ (Steady-State) Flame Strength for $100 \% \mathrm{C}_{2} \mathrm{H}_{4}$-air can be compared with $\mathrm{FS}$ 's for $100 \%$ $\mathrm{CH}_{4}$-air and $18 \% \mathrm{H}_{2}$-air CFDF's obtained using the same $7.2 \mathrm{~mm} \mathrm{OJB}$, and $100 \% \mathrm{H}_{2}$-air CFDF's characterized earlier using scaled OJB's [Pellett et al, Comb. \& Flame, 112:575-592 (1998)]. Based on the present FS of $114.3 \mathrm{~cm} / \mathrm{s}$ at $300 \mathrm{~K}$ for $\mathrm{CH}_{4}$-air $\left(2 U_{\text {air }} / D_{\mathrm{n}}=3181 / \mathrm{s}\right.$, global axial strain rate $)$, the $\mathrm{C}_{2} \mathrm{H}_{4}$-air flame is 2.98 times stronger. And yet, based on previous (and more recent) $\mathrm{H}_{2}$-air results, the $\mathrm{C}_{2} \mathrm{H}_{4}$-air flame is 12.0 times weaker than a $100 \% \mathrm{H}_{2}$-air CFDF.

(3) Dynamic FS varied linearly with pk/pk $U_{\text {air }}$ (velocity magnitude, $\mathrm{HW}$ ), and also pk/pk $P$ (pressure magnitude, PM) at nozzle exits. A complete set of PM cold-flow measurements effectively normalizedout (accounted-for) large acoustic resonance apparatus effects in the dynamic FS data. The Dynamic FS data were also normalized by $0 \mathrm{~Hz}$ (SS) FS. Thus Dynamic Flame Weakening (DFW) was defined as $\%$ decrease in FS per Pascal of pk/pk $P$ oscillation, namely, DFW $=-100 \mathrm{~d}\left(U_{\text {air }} / U_{\text {air }, \mathrm{Hz}}\right) / \mathrm{d}(\mathrm{pkpk} P)$.

(4) For the $\mathrm{C}_{2} \mathrm{H}_{4} / \mathrm{N}_{2}$-air system: From 8 to $20 \mathrm{~Hz}$, DFW is constant at $8.52 \pm 0.2(\%$ weakening)/Pa, and surprisingly independent of $\mathrm{C}_{2} \mathrm{H}_{4} / \mathrm{N}_{2}$ mole fraction. This reflects a "quasi-steady flame response" to an acoustically induced $\mathrm{d} U_{\text {air }} / \mathrm{d} P$. From 20 to $\sim 150 \mathrm{~Hz}$, the $\mathrm{C}_{2} \mathrm{H}_{4} / \mathrm{N}_{2}$-air flames weaken progressively less, with an inflection at $\sim 70 \mathrm{~Hz}$, and become asymptotically insensitive (DFW $\sim 0$ ) at $\sim 300 \mathrm{~Hz}$, which continues out to $1600 \mathrm{~Hz}$. The DFW of $\mathrm{CH}_{4}$-air flames follows a similar pattern, but shows much greater weakening than $\mathrm{C}_{2} \mathrm{H}_{4} / \mathrm{N}_{2}$-air flames; i.e., the quasi-steady DFW of $\mathrm{CH}_{4}$-air (8 to $15 \mathrm{~Hz}$ ) is 44.3 $\% / \mathrm{Pa}$, or $\sim 5 \mathrm{x}$ larger, even though the $0 \mathrm{~Hz}$ steady-state $\mathrm{FS}$ is only $3.0 \mathrm{x}$ smaller. The quasi-steady DFW's of $\mathrm{C}_{3} \mathrm{H}_{8}$-air and $\mathrm{C}_{2} \mathrm{H}_{6}$-air are intermediate at 34.8 and $20.9 \% / \mathrm{Pa}$, respectively.

(5) Thus DFW responses for $f<15 \mathrm{~Hz}$ are effectively quasi-steady. At higher frequencies, DFW remains significant but decreases progressively, apparently reflecting increasing internal phase lags in diffusive transport. A practical high-f limit for DFW is effectively $\sim 200 \mathrm{~Hz}$, beyond which the flames become essentially insensitive to input flow oscillations out to $1600 \mathrm{~Hz}$, the limit of the study.

(6) Respective DFW's at various frequencies, of $\mathrm{CH}_{4}$-air, $\mathrm{C}_{3} \mathrm{H}_{8}$-air, $\mathrm{C}_{2} \mathrm{H}_{6}$-air, and $\mathrm{C}_{2} \mathrm{H}_{4} / \mathrm{N}_{2}$-air flames (in order of decreasing DFW), correlate remarkably well with Steady State FS's (increasing SS FS's). Power law exponents vary from -1.5 for Quasi-SS limits at $<15 \mathrm{~Hz}$, to -1.0 at $100-200 \mathrm{~Hz}$, to $\sim 0$ beyond $300 \mathrm{~Hz}$. The Quasi-SS boundary marks the greatest DFW that can be observed.

(7) The DFW of $\mathrm{C}_{2} \mathrm{H}_{4} / \mathrm{N}_{2}$-air is independent of $\mathrm{N}_{2}$ dilution over a relatively wide range, due to normalization of the (PM-normalized) dynamic Flame Strength by SS Flame Strength. This is likely true for the other hydrocarbon-air systems. Thus the characteristic Dynamic Flame Weakening of each hydrocarbon-air system appears unique to the combustion kinetics of that system.

(8) Finally, systematic Fuel-Air input phase effects were measured for the $\mathrm{C}_{2} \mathrm{H}_{4} / \mathrm{N}_{2}$-air system, but the relative changes in DFW appeared both complex and relatively small. 
In conclusion, Dynamic Flame Weakening limits appear significant and unique for each fuel, and correlate closely, but non-linearly, with Steady-State Flame Strengths. The Dynamic Weakening of methane flames is much greater than for ethylene flames, up to nearly $200 \mathrm{~Hz}$. For reasons unknown, the Dynamic Weakening of flames didn't increase at intermediate frequencies (e.g., at 20$50 \mathrm{~Hz}$ ) compared to low frequencies $(<15 \mathrm{~Hz})$, where quasi-steady weakening appears to dominate. Quasi-steady weakening ostensibly corresponds to the peak input strain rate just exceeding the steadystate extinction limit for a few cycles. Clearly, further detailed mechanistic understanding is needed in the fall-off region.

The fundamental results of this study may apply to airbreathing scramjet engines in which critical early stages of localized subsonic flameholding are associated with fuel injection processes that "feed" recirculation zones having "sufficient" residence-time distribution. Important phenomena may include acoustic resonance in cavity flameholders and fuel-injector wakes; near-field coupling with subsonic vortex shedding; and dynamic coupling with unsteady fuel injection systems. Incipient flames may be weakened or extinguished by acoustically driven strain-rate and frequency sensitive processes, such as $\mathrm{H}$-atom diffusion in a "laminar-flamelet-like" reaction zone. Because such limitations may cause the loss of "robust" flameholding, and possibly generalized flameout, it appears important to characterize these dynamic effects and assess the potential for occurrence in scramjet and other combustor designs. Measurements of acoustic fields are needed to assess possible effects of localized acoustic fields on critical flameholding in ground-based and flight tests of scramjet engine configurations.

\section{References}

1. Clarke, J.F., and Stegen, G.R., "Some Unsteady Motions of a Diffusion Flame Sheet," J. Fluid Mech., 34: part 2, 1968, pp. 343-358.

2. Saitoh, T., and Otsuks, Y., "Unsteady Behavior of Diffusion Flames and Premixed Flames for Counter Flow Geometry," Comb. Sci. Tech. 12: 1976, pp. 135-146.

3. Stahl, G., and Warnatz, J., "Numerical Investigation of Time-Dependent Properties and Extinction of Strained Methane- and Propane-Air Flamelets," Combust. Flame, 85: 1991, pp. 285-299.

4. Ghoniem, A.F., Soteriou, M.C., and Knio, O.M., "Effect of Steady and Periodic Strain on Unsteady Flamelet Combustion," Twenty-Fourth Symposium (International) on Combustion, The Combustion Institute,1992, pp. 223-230.

5. Darabiha, N., "Transient Behavior of Laminar Counterflow Hydrogen-Air Diffusion Flames with Complex Chemistry," Comb. Sci. Tech., 86: 163-181 (1992).

6. Kim, J.S. and Williams, F.A., "Contribution of Strained Diffusion Flames to Acoustic Pressure Response," Combust. Flame, 98: 1994, pp. 279-299.

7. Egolfopoulos, F.N., "Dynamics and Structure of Unsteady, Strained, Laminar Premixed Flames, Twenty-Fifth Symposium (International) on Combustion, The Combustion Institute,1994, pp. 13651373.

8. Im, H.G, Bechtold, J.K. and Law, C.K., "Counterflow Diffusion Flames with Unsteady Strain Rates," AIAA Paper 95-0128, Jan., 1995, 9 pp.

9. Im, H.G., Law, C.K., Kim, J.S. and Williams, F.A., "Response of Counterflow Diffusion Flames to Oscillating Strain Rates," Combust. Flame, 100: 21-30 (1995). 
10. Brown, T.M., and Pitz, R.W., "Experimental Investigation of Counterflow Diffusion Flames with Oscillatory Stretch," AIAA Paper 96-0124, Jan. 1996.

11. Egolfopoulos, F. and Campbell, C.S., "Unsteady Counterflowing Strained Diffusion Flames: Diffusion-Limited Frequency Response," J. Fluid Mech. 318: 1996, pp. 1-29.

12. Kistler, J.S., Sung, C.J., Kreutz, T.G., Law, C.K., Nishioka, M., "Extinction of Counterflow Diffusion Flames Under Velocity Oscillations," Twenty-Sixth Symposium (International) on Combustion, The Combustion Institute, 1996, pp. 113-120.

13. Brown, T.M., Pitz, R.W., and Sung, C.J., "Oscillatory Stretch Effects on the Structure and Extinction of Counterflow Diffusion Flames," Twenty-Seventh Symposium (International) on Combustion, The Combustion Institute, 1998, pp. 703-710.

14. Decroix, M.E., and Roberts, W.L., "Study of Transient Effects on the Extinction Limits of an Unsteady Counterflow Diffusion Flame," Combust. Sci and Tech.146: 1999, pp. 57-84.

15. Welle, E.J., Roberts, W.L., Donbar, J.M., Carter, C.D., DeCroix, M.E., "Simultaneous PIV and OHPLIF Measurements in an Unsteady Counterflow Propane-Air Diffusion Flame," Proceedings of the Combustion Institute, 28, 2001, pp. 2021-2027.

16. Pellett, G.L., Northam, G.B., Wilson, L.G., "Counterflow Diffusion Flames of Hydrogen, and Hydrogen Plus Methane, Ethylene, Propane, and Silane, vs. Air: Strain Rates at Extinction," AIAA Paper 91-0370, Jan., 1991, 17 pp.

17. Pellett, G.L., Northam, G.B., Wilson, L.G., "Strain-Induced Extinction of Hydrogen-Air Counterflow Diffusion Flames: Effects of Steam, $\mathrm{CO}_{2}, \mathrm{~N}_{2}$, and $\mathrm{O}_{2}$ Additives to Air," AIAA Paper 92-0877, Jan., 1992, $15 \mathrm{pp}$. (Also an unpublished manuscript on these results, and recent 2-D numerical and experimental results -- to be published.)

18. Pellett, G. L., Roberts, W. L., Wilson, L. G., Humphreys, W. M., Jr., Bartram, S. M., Weinstein, L. M., and Isaac, K. M., "Structure of Hydrogen-Air Counterflow Diffusion Flames Obtained by Focusing Schlieren, Shadowgraph, PIV, Thermometry, and Computation," AIAA Paper 94-2300, June 1994, 23 pp.

19. Pellett, G. L., Wilson, L. G., Humphreys, W. M.,Jr., Bartram, S. M., Gartrell, L. R., and Isaac, K. M., Roberts, W. L., IV, and Northam, G. B., "Velocity Fields of Axisymmetric Hydrogen-Air Counterflow Diffusion Flames from LDV, PIV, and Numerical Computation," AIAA paper 95-3112, July 1995, 23 pp.

20. Isaac, K. M., Ho, Y. H., Zhao, J., Pellett, G. L., and Northam, G. B., "Global Characteristics and Structure of Hydrogen-Air Counterflow Diffusion Flames: A One-Dimensional Model," AIAA Paper 940680, Jan.,1994. Also, Zhao, J., Isaac, K. M., and Pellett, G. L., J. Propul. Power 12, No. 3: 534-542 (1996).

21. Pellett, G.L., Isaac, K.M., Humphreys, W.M., Jr., Gartrell, L.R., Roberts, W.L., Dancey, C.L., and Northam, G.B., "Velocity and Thermal Structure, and Strain-Induced Extinction of 14 to $100 \%$ Hydrogen-Air Counterflow Diffusion Flames," Combust. Flame 112, No. 4, 1998, pp. 575-592.

22. Pellett, G.L., Bruno, C., and Chinitz, W., "Review of Air Vitiation Effects on Scramjet Ignition and Flameholding Combustion Processes," AIAA Paper 2002-3880, July, 2002, 37 pp.

23. Frouzakis, C.E., Lee, J., Tomboulides, A.G., and Boulouchos, K., "Two-Dimensional Direct Numerical Simulation of Opposed-Jet Hydrogen-Air Diffusion Flame," Twenty-Seventh Symposium (International) on Combustion, The Combustion Institute, 1998, pp. 571-577. 
24. Lee, J., Frouzakis, C.E., and Boulouchos, K., "Two-Dimensional Direct Numerical Simulation of Opposed-Jet Hydrogen-Air Diffusion Flames: Transition from a Diffusion to an Edge Flame,"

Proceedings of the Combustion Institute, 28, 2000, pp. 801-806.

25. Ben-Yakar and Hanson, R.K., "Cavity Flameholders for Ignition and Flame Stabilization in Scramjets: Review and Experimental Study," AIAA Paper 98-3122, July 1998, 17 pp.

26. Pellett, G.L., Reid, Beth, McNamara, Clare, Johnson, Rachel, Kabaria, Amy, Panigrahi, Babita, and Wilson, L.G., "Acoustic Weakening of Methane-, Ethylene-, and Hydrogen-Air Counterflow Diffusion Flames, and Implications for Scramjet Flameholding." AIAA Paper 2003-4634, July, 2003, 21 pp.

27. Pellett, G., Reid, B., McNamara, C., Johnson, R., Kabaria, A., Panigrahi, B., Sammons, K., and Wilson, L., "Dynamic Weakening of $\mathrm{CH}_{4}-, \mathrm{C}_{2} \mathrm{H}_{6}-$, and $\mathrm{C}_{2} \mathrm{H}_{4} / \mathrm{N}_{2}$-Air Counterflow Diffusion Flames using Acoustically Perturbed Inflows." Work-in-Progress Poster Paper 4F504, Presented at $30^{\text {th }}$ International Symposium on Combustion, Abstracts of Work-In-Progress Posters, The Combustion Institute, Pittsburgh, PA, July 25-30, 2004.

28. Hwang, Kyu C., "Two Dimensional Numerical Simulation of Highly-Srained Hydrogen-Air Opposed Jet Laminar Diffusion Flames," Ph. D. Dissertation, Old Dominion University, Norfolk, VA, May, 2003.

29. Convery, J.L., Pellett, G.L., O' Brien, W.F., and Wilson, L.G., "An Experimental Study of $n$-Heptane and JP-7 Extinction Limits in an Opposed Jet Burner," AIAA Paper 2005-3766, July, 2005, 8 pp. 


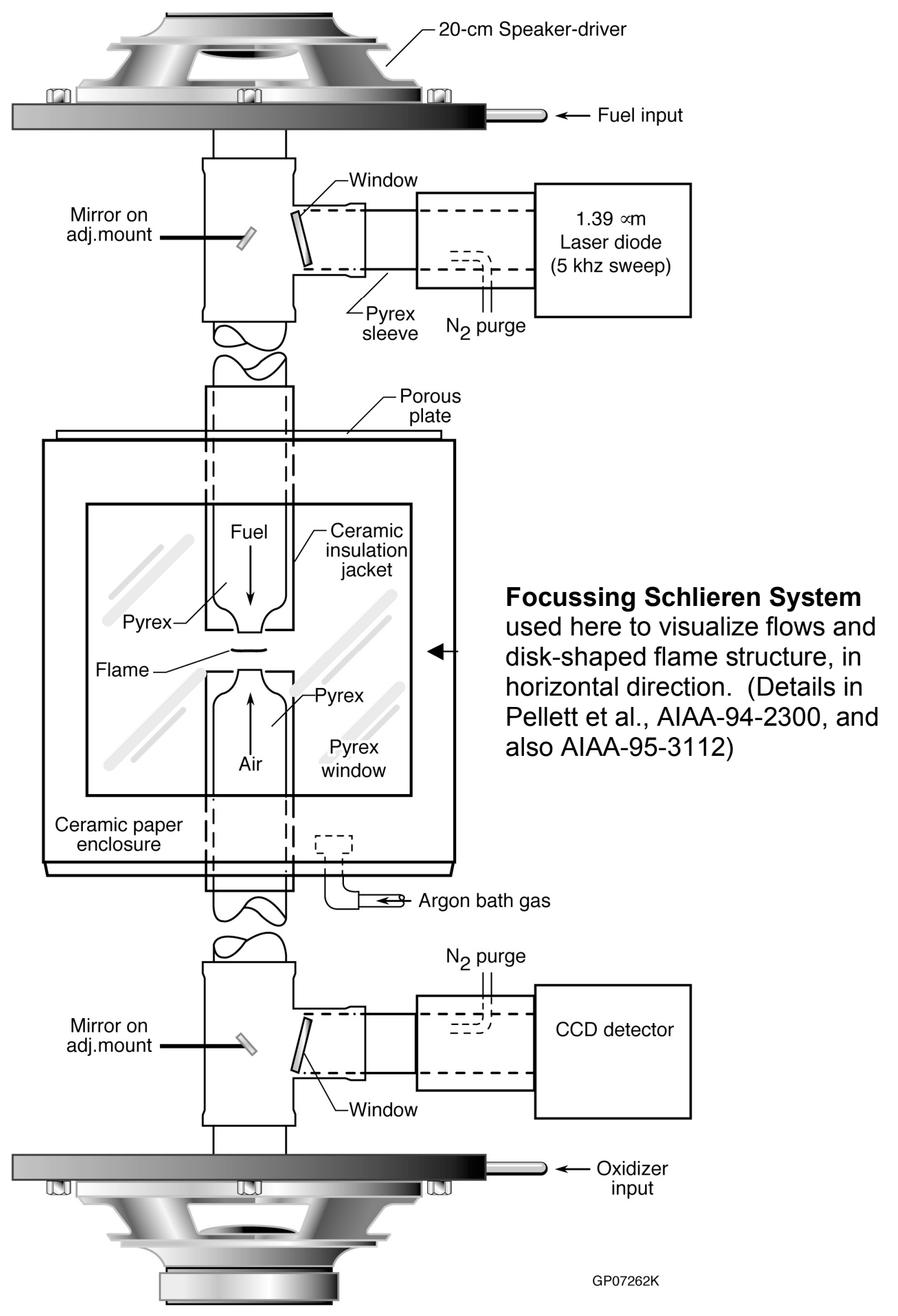

Fig. 1. Schematic of Oscillatory Opposed Jet Burner (OOJB) system with twin $20-\mathrm{cm}$ speaker-drivers. Diode laser system is passive in this study. 


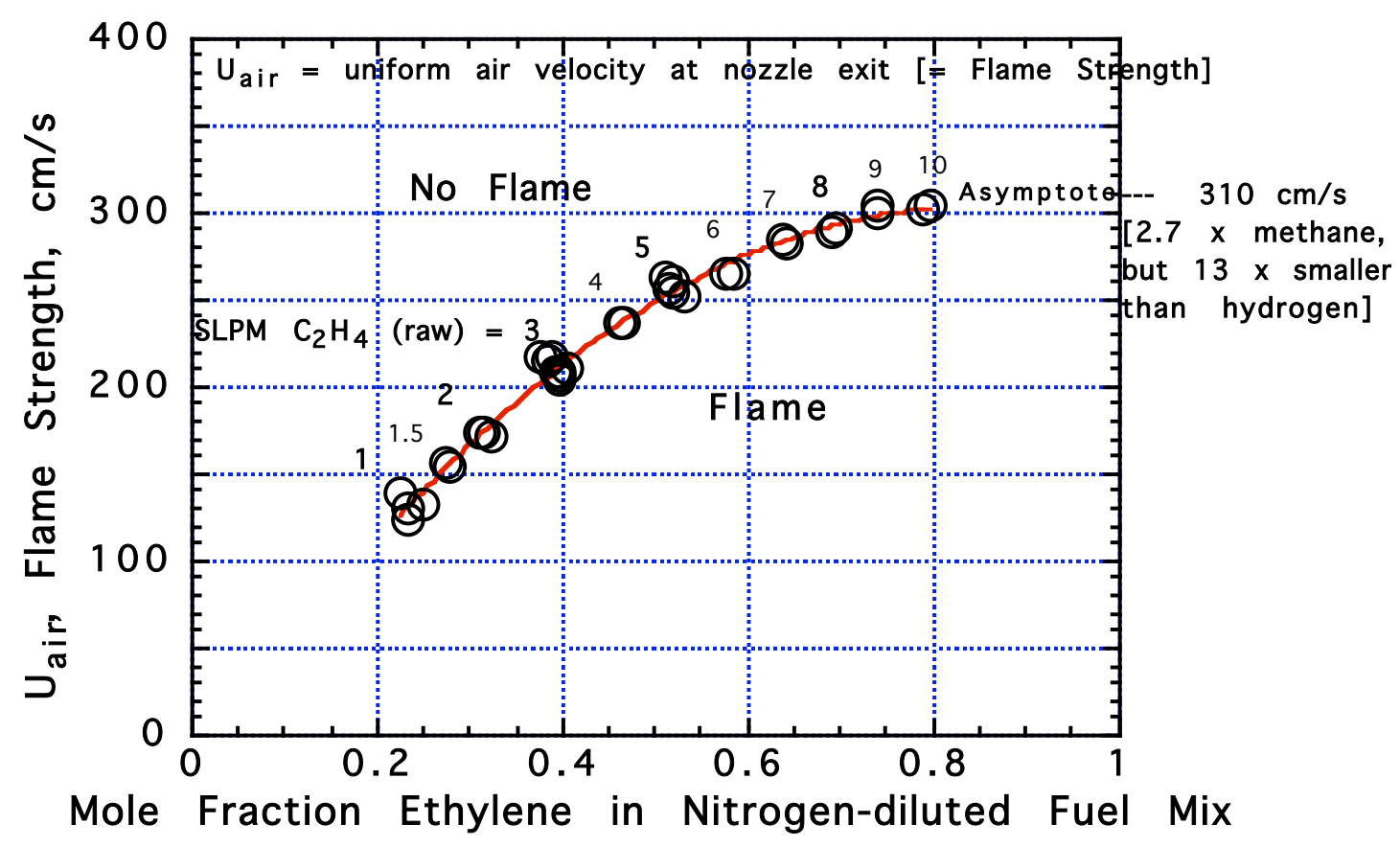

Fig. 2. Flame Strength at Steady-State extinction of $\mathrm{C}_{2} \mathrm{H}_{4} / \mathrm{N}_{2}-$ Air Counterflow Diffusion Flames (CFDF's), using $7.2 \mathrm{~mm}$ Pyrex Nozzle OOJB. $U_{\text {air }}$ is standardized at $273 \mathrm{~K}, 1 \mathrm{~atm}$.

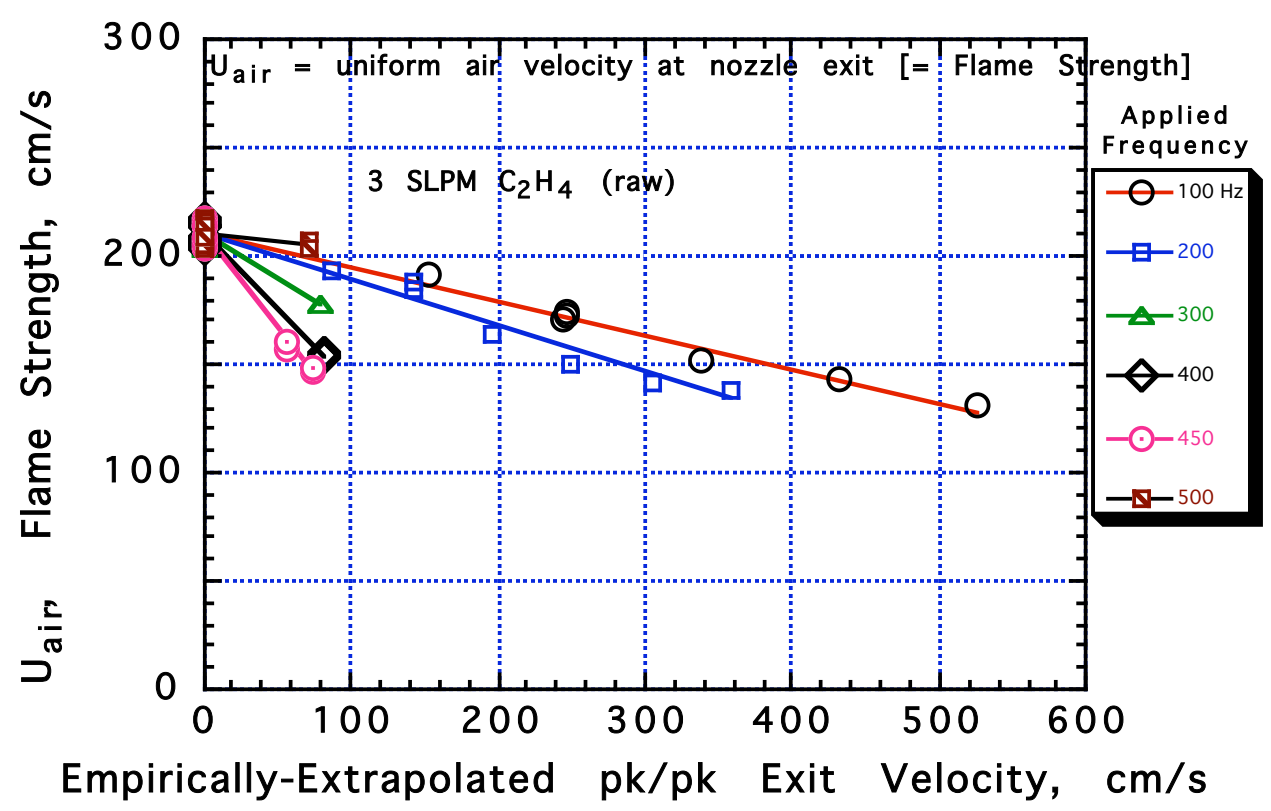

Fig. 3. Dynamic extinction of $\mathrm{C}_{2} \mathrm{H}_{4} / \mathrm{N}_{2}$-Air CFDF's using $7.2 \mathrm{~mm}$ Pyrex nozzle OOJB, with axially-applied in-phase sinusoidal velocity inputs. Abscissa is based on an empirical analysis of Hot-Wire Velocimetry data on nozzle-exit cold-air flows, from $25-120 \mathrm{~Hz}$, and then an extrapolation of the tested empirical pk/pk exit velocity expression to higher frequencies. 


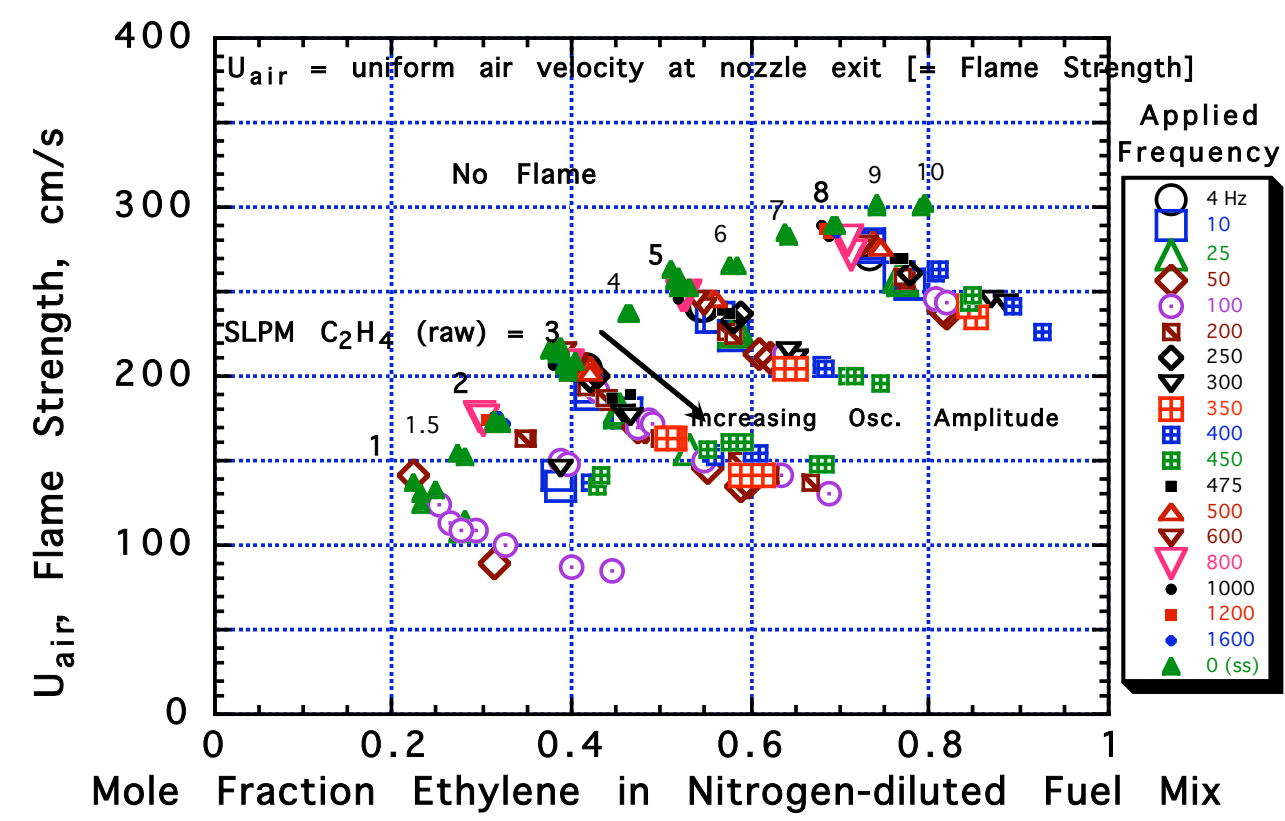

Fig. 4. Steady-State and dynamic extinction of $\mathrm{C}_{2} \mathrm{H}_{4} / \mathrm{N}_{2}$-Air CFDFs, using $7.2 \mathrm{~mm}$ Nozzle OOJB with 1- 10 SLPM $\mathrm{C}_{2} \mathrm{H}_{4}$ Flows, and axially-applied in-phase sinusoidal velocity inputs of $\mathrm{C}_{2} \mathrm{H}_{4} / \mathrm{N}_{2}$ and air at varied amplitude and frequency. Early data up to 11/02 are included here.

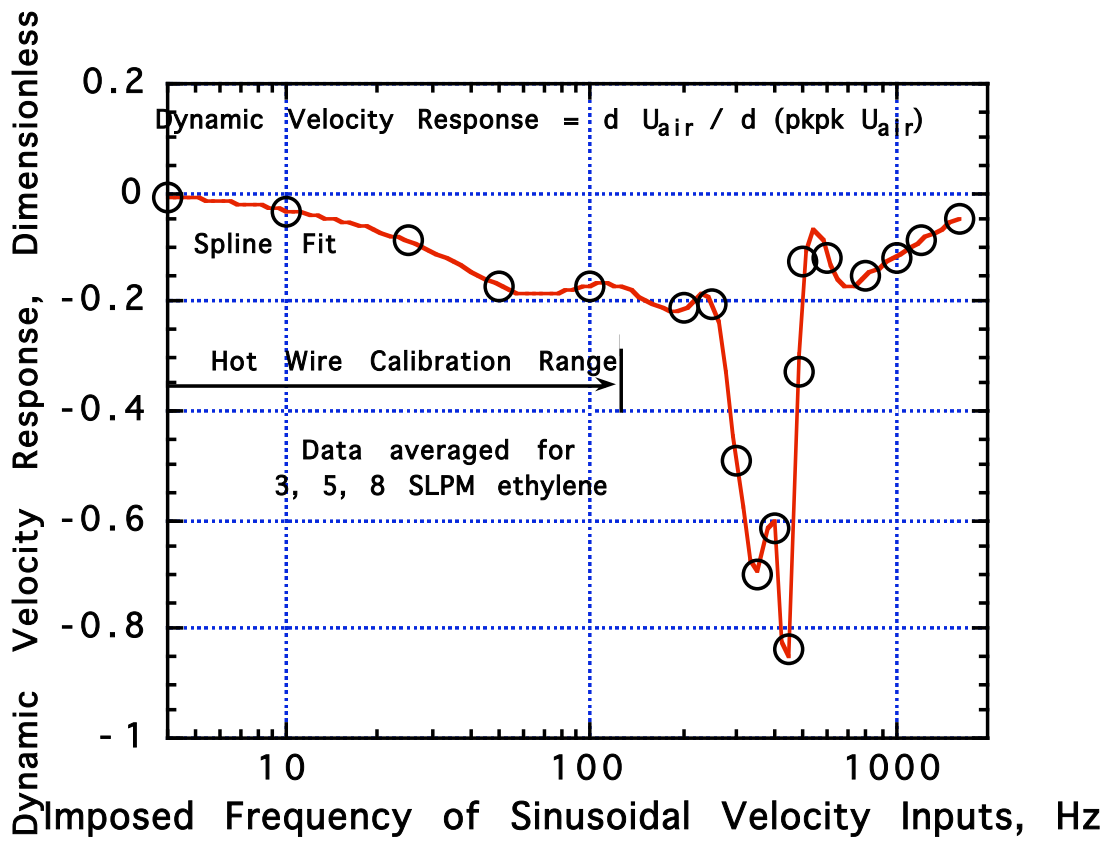

Fig. 5. Dynamic Velocity Response for extinction of $\mathrm{C}_{2} \mathrm{H}_{4} / \mathrm{N}_{2}-$ Air CFDF's, using $7.2 \mathrm{~mm}$ Pyrex nozzle OOJB with 3,5, 8 SLPM C $\mathrm{H}_{4}$ flows, and axial sinusoidal velocity inputs. Dynamic Velocity Response is based on $\mathrm{pk} / \mathrm{pk}$ nozzle exit air velocities that were originally derived from Hot Wire measurements on cold air and $\mathrm{N}_{2}$ flows at $25-120 \mathrm{~Hz}$, and then empirically projected at higher frequencies. 


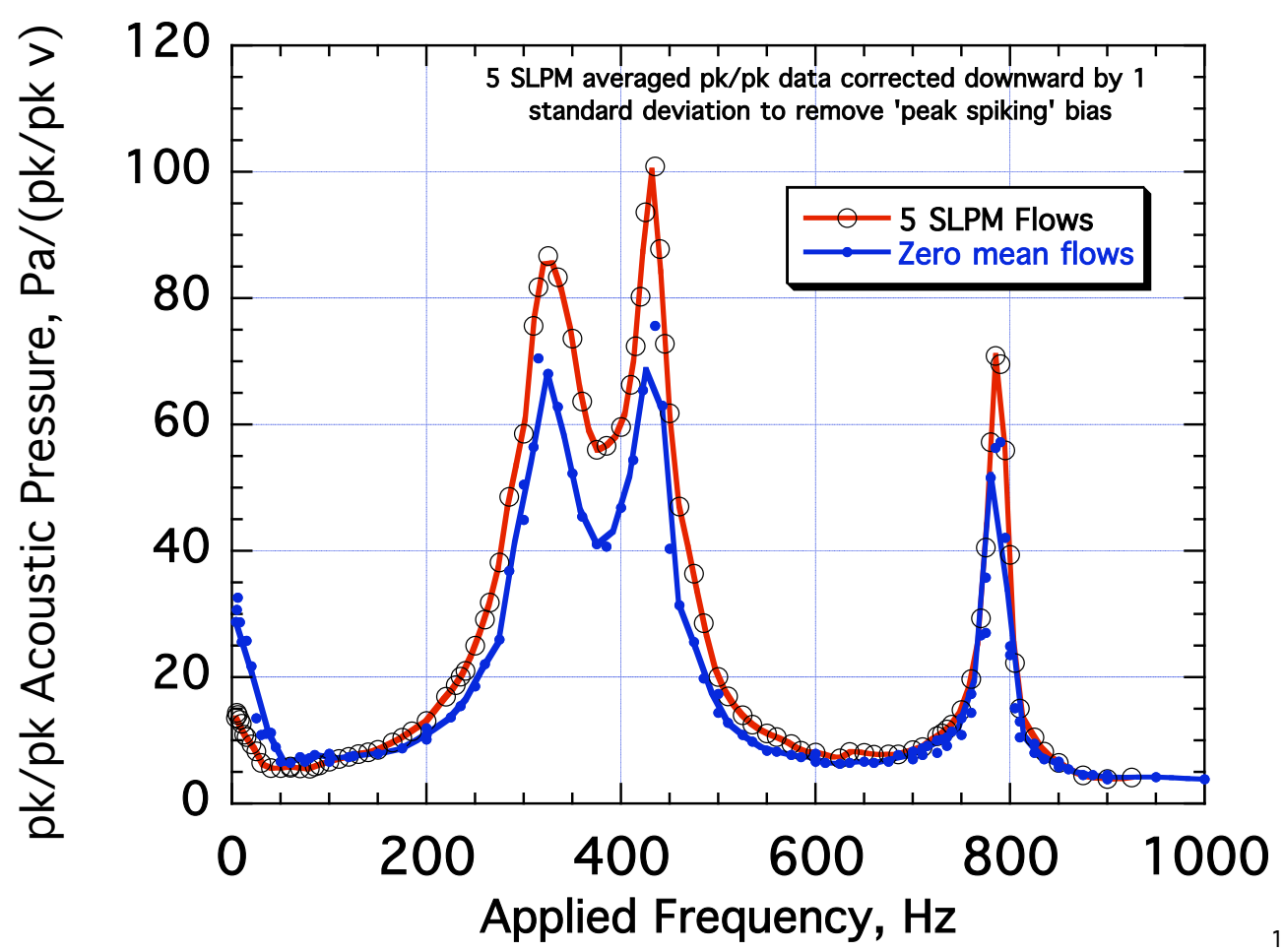

$11 / 13 / 03$

Fig. 6. Normalized Probe Microphone response of sinusoidal speaker-driver sound pressure at exit plane ( $\mathrm{r} / \mathrm{a}=0.5$ ) of $7.2 \mathrm{~mm}$ Pyrex (air) nozzle, for both 0 and 5 SLPM Air and Fuel flows (air also used for fuel side), using calibrated Probe Microphone with both 50 and $100 \mathrm{~mm}$ long probe tubes. The pk/pk voltage magnitude applied to the speaker-drivers is normalized to 1.0 volt in this calibration. 


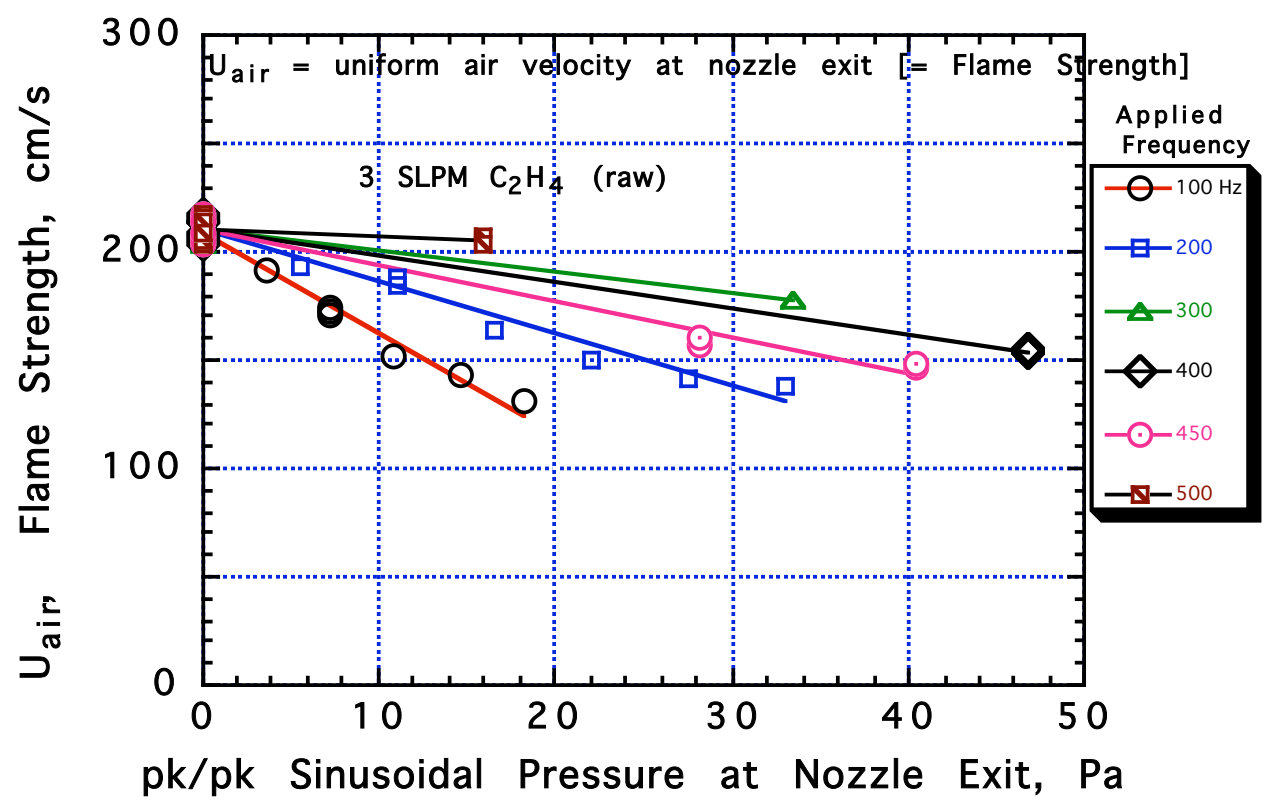

Fig. 7. Dynamic Extinction of $\mathrm{C}_{2} \mathrm{H}_{4} / \mathrm{N}_{2}$-Air CFDF's, for 3 SLPM C ${ }_{2} \mathrm{H}_{4}$ (raw mass flows), using 7.2 $\mathrm{mm}$ Nozzle OOJB with axially-applied sinusoidal velocity inputs. Abscissa is based on Probe Microphone pressure measurements of sound at nozzle exit with zero mean flow, shown in Fig. 6.

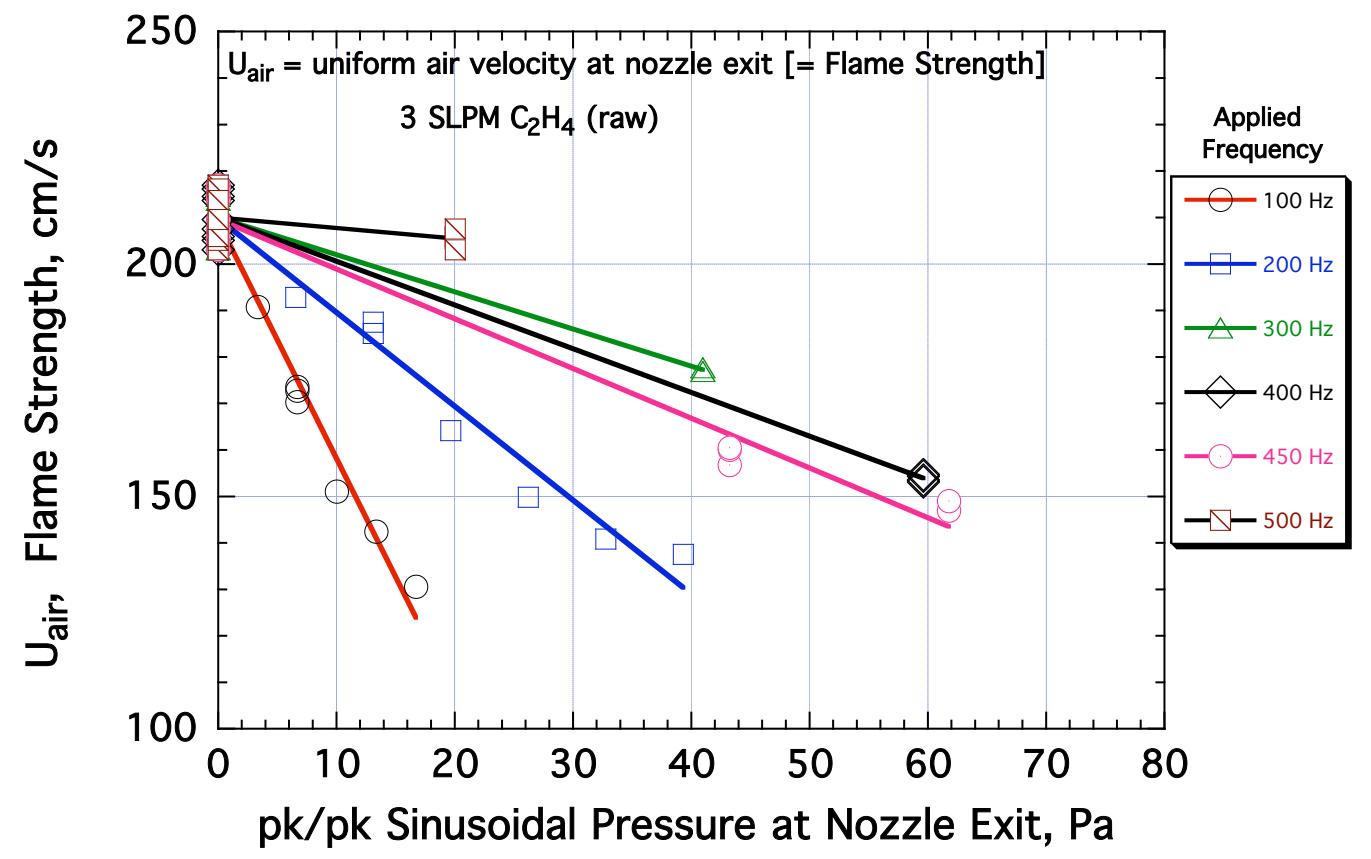

Fig. 8. Dynamic Extinction of $\mathrm{C}_{2} \mathrm{H}_{4} / \mathrm{N}_{2}$-Air CFDF's, for 3 SLPM $\mathrm{C}_{2} \mathrm{H}_{4}$ inputs, using $7.2 \mathrm{~mm}$ Nozzle OOJB with axially-applied sinusoidal velocity inputs. Abscissa is based on Probe Microphone pressure measurements of sound at nozzle exit with 5 SLPM flow, shown in Fig. 6. 


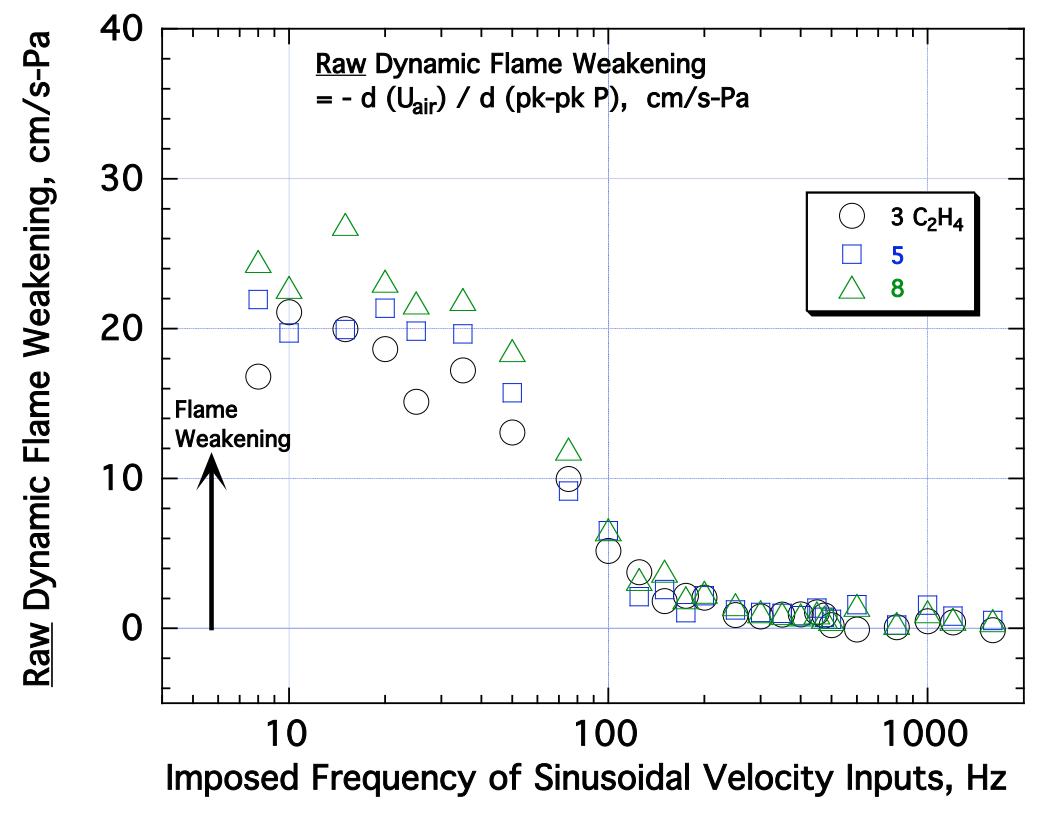

$7 / 7 / 05$.

Fig. 9. Raw Dynamic Flame Weakening for extinction of $\mathrm{C}_{2} \mathrm{H}_{4} / \mathrm{N}_{2}$ vs Air CFDFs, using $7.2 \mathrm{~mm}$ Pyrex Nozzle OOJB, referenced to axially-applied sinusoidal velocity (pressure) Inputs probed by Microphone (cal. @ 5 SLPM)

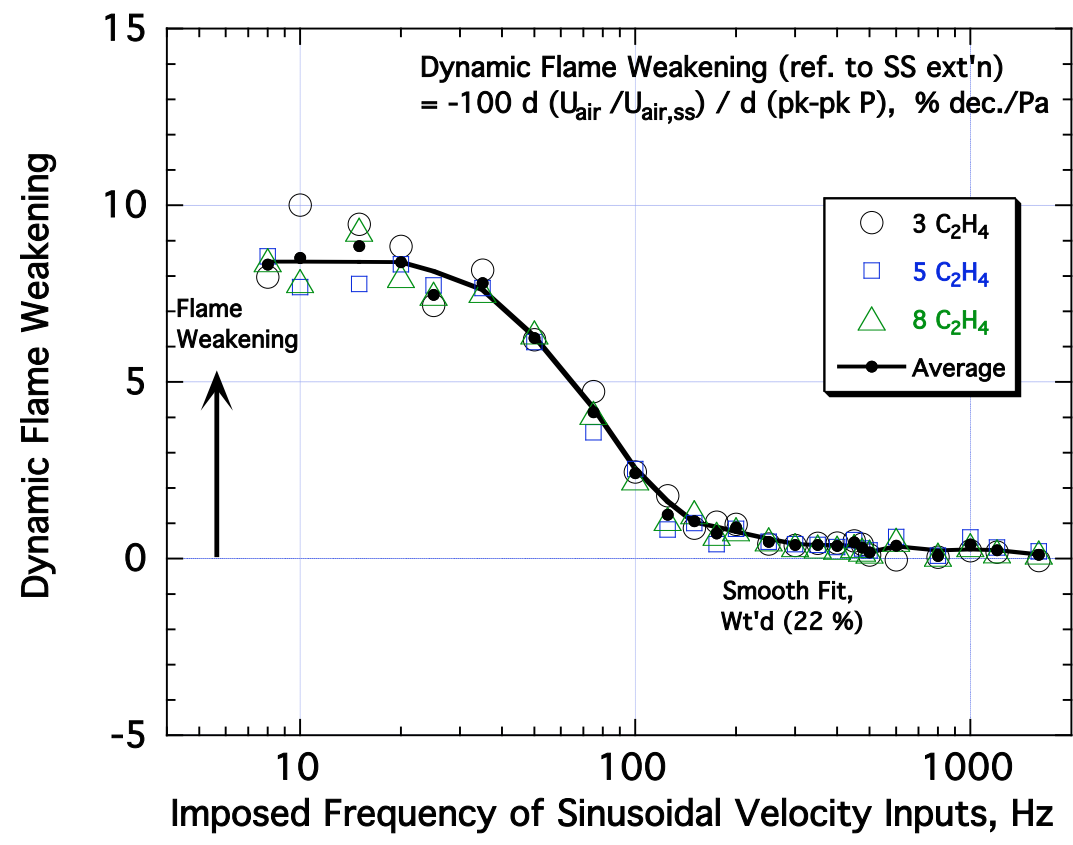

Fig. 10. Fully normalized Dynamic Flame Weakening of $\mathrm{C}_{2} \mathrm{H}_{4} / \mathrm{N}_{2}$-Air CFDF's in Fig. 9, using 7.2 $\mathrm{mm}$ Pyrex Nozzle OOJB and measurements of axially-applied sinusoidal velocity inputs probed by Microphone with 5 SLPM flows. Note that normalization collapsed the three sets of ethylene results to an equivalent response that is independent of dilution by $\mathrm{N}_{2}$. 




Fig. 11. Dynamic Flame Weakening of all HC-Air CFDF systems studied: $\mathrm{C}_{2} \mathrm{H}_{4} / \mathrm{N}_{2}, \mathrm{C}_{2} \mathrm{H}_{6}$, $\mathrm{C}_{3} \mathrm{H}_{8}$, and $\mathrm{CH}_{4}$ vs Air, using $7.2 \mathrm{~mm}$ Pyrex Nozzle OOJB and measurements of axiallyapplied sinusoidal velocity inputs probed by Microphone with 5 SLPM flows. Note the three sets of ethylene results are equivalent, and independent of dilution by $\mathrm{N}_{2}$. 


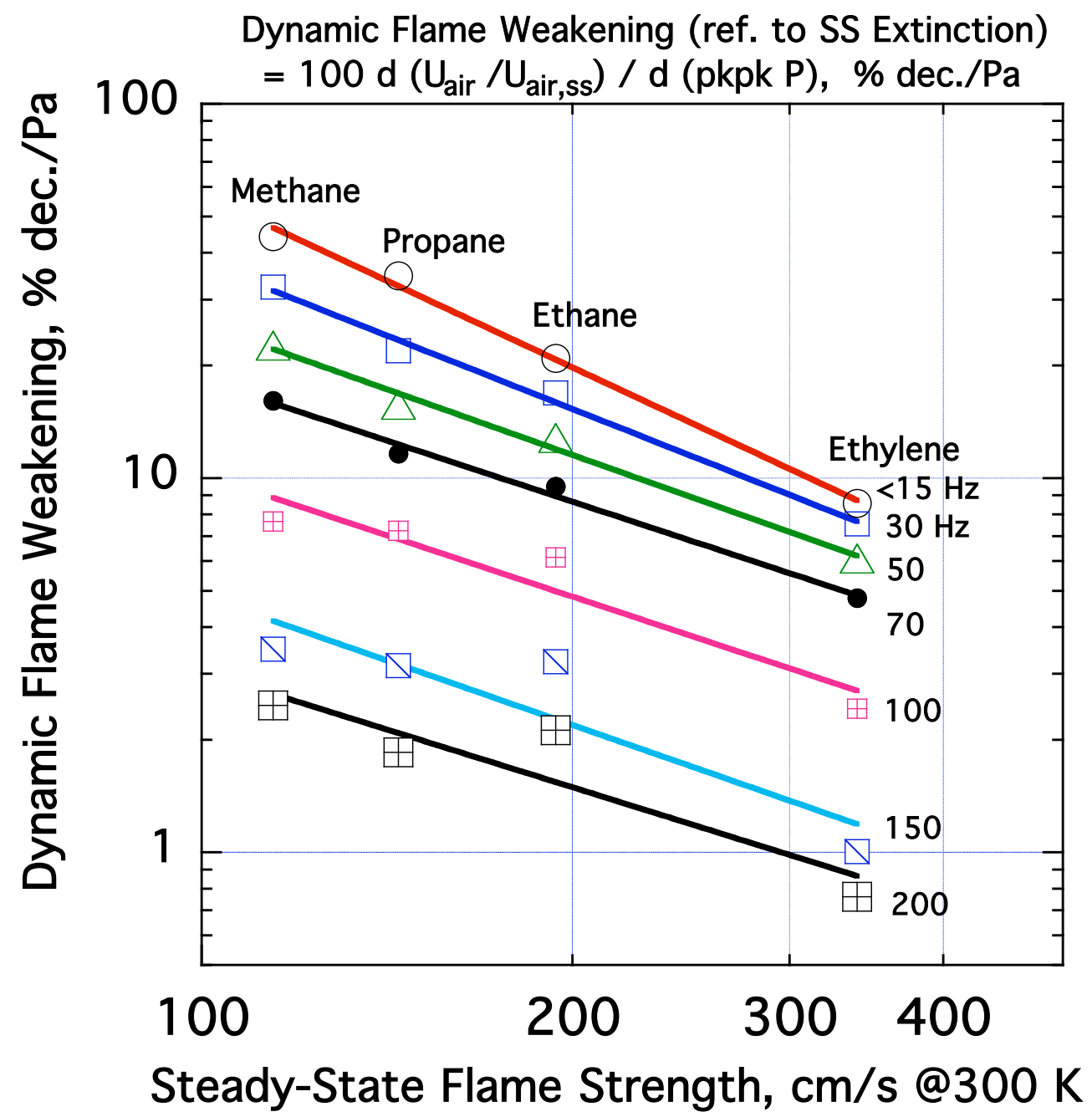

$6 / 22 / 05$

Fig. 12. Summary crossplot of Dynamic Flame Weakening vs frequency results in Fig. 11, as a function of Steady State Flame Strength, for all HC-Air CFDF systems studied. All results are referenced to axially applied sinusoidal velocity inputs probed by microphone with $\mathbf{5}$ SLPM flows. The Quasi-Steady-State results for $\mathrm{f}<15 \mathrm{~Hz}$ represent an upper bound on DFW. 


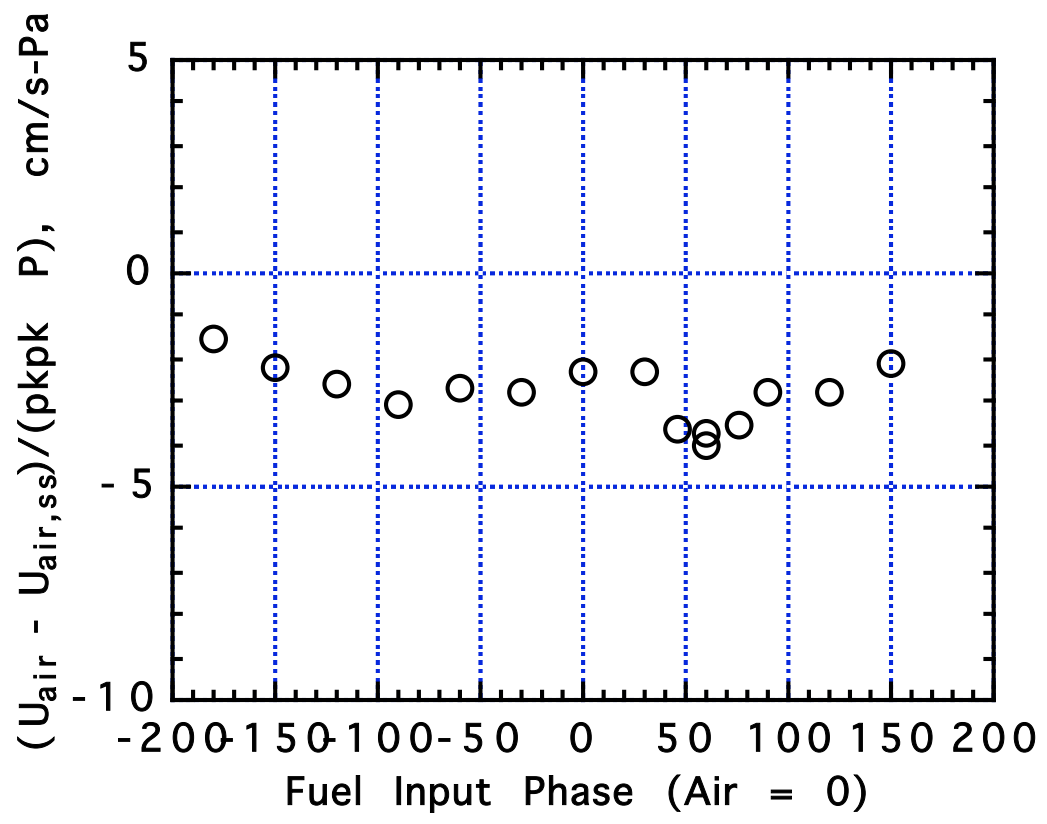

Fig. 13. Effect of Fuel-Air Phase difference on dynamic extinction response of $\mathrm{C}_{2} \mathrm{H}_{4}$-Air CFDFs, using $7.2 \mathrm{~mm}$ Pyrex Nozzle OOJB with 3 SLPM $\mathrm{C}_{2} \mathrm{H}_{4}$ Flows, and $150 \mathrm{~Hz}$ axially applied sinusoidal velocity inputs probed by Microphone.

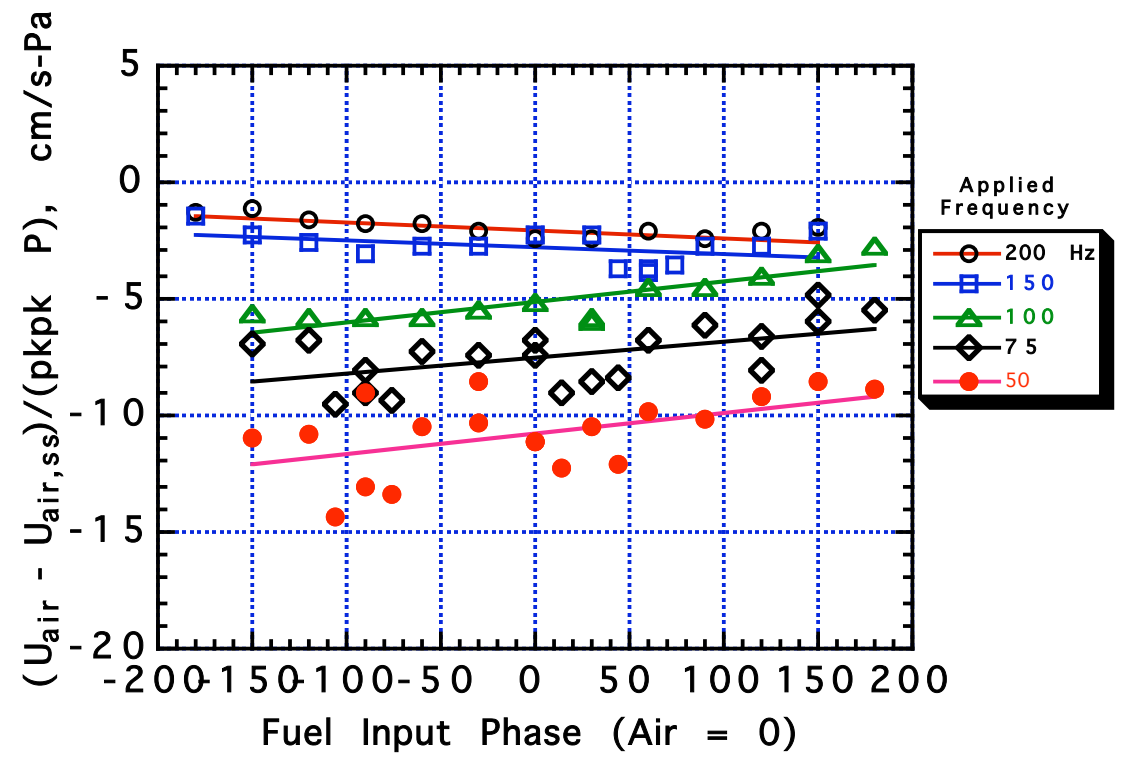

Fig. 14. Effect of Fuel-Air Phase difference on dynamic extinction Flame responses of $\mathrm{C}_{2} \mathrm{H}_{4}$-Air CFDFs at four key frequencies, using $7.2 \mathrm{~mm}$ Pyrex Nozzle OOJB with 3 SLPM $\mathrm{C}_{2} \mathrm{H}_{4}$ flows, and axially-applied sinusoidal velocity Inputs probed by Microphone. 